\title{
\begin{tabular}{l|l} 
Mitraries & DSpace@MIT
\end{tabular}
}

\author{
MIT Open Access Articles
}

\section{Paying with money or effort: Pricing when customers anticipate hassle}

The MIT Faculty has made this article openly available. Please share how this access benefits you. Your story matters.

Citation: Lambrecht, Anja, and Catherine Tucker. “Paying with Money or Effort: Pricing When Customers Anticipate Hassle." Journal of Marketing Research 49.1 (2012): 66-82.

As Published: http://dx.doi.org/10.1509/jmr.09.0530

Publisher: American Marketing Association

Persistent URL: http://hdl.handle.net/1721.1/75860

Version: Author's final manuscript: final author's manuscript post peer review, without publisher's formatting or copy editing

Terms of use: Creative Commons Attribution-Noncommercial-Share Alike 3.0 


\title{
Paying With Money or With Effort: Pricing When Customers Anticipate Hassle
}

\author{
Anja Lambrecht* \\ London Business School \\ alambrecht@london.edu \\ Catherine Tucker ${ }^{+}$ \\ MIT Sloan School of Management \\ cetucker@mit.edu
}

*Anja Lambrecht, Assistant Professor of Marketing, London Business School, Regent's Park, London NW1 4SA, United Kingdom, tel: +44 (0) 207000 8645, fax: +44 (0) 207000 8601, email: alambrecht@london.edu

${ }^{+}$Catherine Tucker, Assistant Professor of Marketing, MIT Sloan School of Management, 100 Main St E62-533, Cambridge MA 02142, USA, tel: +1 (617) 252 1499, fax: +1 (617) 258-7597, email: cetucker@mit.edu

Anja Lambrecht thanks Deutsche Forschungsgemeinschaft, the London Business School Center of Marketing and the Institute of Innovation and Entrepeneurship. The paper benefited from discussions with Marco Bertini, Simona Botti, Rajesh Chandy, David Faro, Shane Frederick, Avi Goldfarb, Monika Heller, Dan Goldstein, Kanishka Misra, John Roberts, Nader Tavassoli and Juanjuan Zhang.

Keywords: Pricing, Services, Field Experiment, Contractual Discounting, Hassle Costs, PeriodLevel Bracketing 


\begin{abstract}
For many services, customers subscribe to long-term contracts. Standard economic theory suggests that customers evaluate a contract as the sum of benefits and payments. We suggest that rather than evaluating multi-period service contracts at the contract-level, customers use periodlevel bracketing. They evaluate the distinct per-period loss or gain they incur from choosing this contract. This has important consequences when benefits vary over the course of the contract, for example due to "hassle costs." If customers use period-level bracketing, they will value a lower price more in periods where they have hassle than in other periods. We explore this using data from a field experiment for web hosting services. The field experiment had 2 hassle cost priming conditions (present, absent) x 2 discount conditions (offered, not offered). We find that a lower price in the initial period is more attractive to customers when they expect their hassle costs to be high at setup. In five lab experiments, we support and extend the field experiment's findings. We find evidence for period-level bracketing when customers have hassle costs, independently of whether hassle costs occur in the first, an intermediate or the last period of a contract. We rule out alternative explanations, such as hyperbolic discounting. Our findings suggest that in setting prices, firms should consider the timing of hassle costs faced by customers.
\end{abstract}




\section{INTRODUCTION}

For many services, such as cell phone, Internet, television or web services, customers commit to a long-term contract with a firm that spans multiple time periods, typically several months. Standard economic theory assumes that a customer evaluates payments and benefits at the contract level and is indifferent about the distribution of payments and benefits within a contract, so long as the total net discounted value of the contract remains the same. We suggest that in multi-period service contracts, customers instead evaluate benefits and payments using period-level bracketing. They evaluate the distinct per-period loss or gain they incur from choosing this contract. As a result, under period-level bracketing customers are not indifferent to the distribution of payments and benefits over time.

Period-level bracketing would affect decision-making when the value of a service varies over time. An important source of such variation is hassle costs. In service contracts, customers often experience hassle in distinct periods. Hassle can arise when setting up a service, such as installing a wireless network at home; maintaining an ongoing service, such as waiting for the satellite TV company to visit and fix a broken connection; or at the end of the contract, like when cancelling a telephone contract. We define "hassle costs” as the non-monetary effort and inconvenience a customer incurs in setting up, maintaining or disposing of a product or service. Hassle costs may prevent customers from entering into contracts or reduce their satisfaction with their existing provider. If customers use period-level bracketing, they will care when hassle occurs within a contract, and should prefer lower payments, for example discounts, at the time of higher hassle costs. This contrasts with standard economic theory that would predict that preferences for a payment schedule should be independent from when customers face hassle costs. 
In our field experiment, we use search advertising to manipulate and consequently identify the effect of customer expectations of hassle costs on pricing plan choice. In five subsequent lab experiments, we vary the timing of hassle costs and the offered pricing plans. Our results provide strong evidence that customers use period-level bracketing, preferring to match the pattern of their payments to the pattern of their hassle costs whether hassle costs arise at the beginning, during or at the end of their service contract. This reflects the fact that firms may impose hassle costs on their consumers during the setup, maintenance, or disposal of a product. They also illustrate how firms can benefit from designing pricing schemes that reduce the payment that a customer makes in the period of hassle, even if the overall amount the firm charges over the contract remains the same.

\section{CONCEPTUAL FRAMEWORK}

\section{Decision-Making for Contracts}

Standard economic principles suggest that customers evaluate a contract based on the net present value of the sum of benefits and payments within a contract. Without loss of generality, let us assume that the discount rate is zero. In period $t$ a customer receives benefit $x_{t}$ from a service, which provides a level of utility, $g\left(x_{t}\right)$, and pays the price $p_{t}$. The coefficient $\lambda$ denotes the transformation of monetary units into utility. The net value of a contract is then evaluated as (1) $V_{T}^{C}=\sum_{t} g\left(x_{t}\right)-\lambda p_{t}$.

We refer to this as contract-level bracketing since the evaluation is based on the total outcome of the contract. We argue that instead consumers may evaluate contracts using periodlevel bracketing. Previous research suggests that consumers tend to evaluate outcomes in distinct time periods, often in relatively narrow time frames (Benartzi and Thaler 1999; Read et al. 
1999). This is true even if events are part of a decision or strategy that spans multiple time periods. For example, there is evidence that individuals' evaluation period of stock market returns are substantially shorter than the full span of their investment horizon (Benartzi and Thaler 1995). Within these evaluation periods, customers aim to achieve the best possible outcomes. These period-level outcomes guide overall decisions.

Therefore when customers are faced with a contract, they evaluate its attractiveness in individual time periods, for example associated with the customary billing cycle, instead of evaluating the full contract as a whole. In each separate period, they wish to achieve the best possible outcome rather than demanding a positive outcome only over the total course of the contract. Prospect theory suggests that rather than evaluating the absolute outcome of a contract, consumers evaluate outcomes as a gain or a loss relative to a reference point (Kahneman and Tversky 1979). If $v($.$) represents the value a consumer assigns to the per-period outcome of a$ contract, the value of this contract across all periods under contract-level bracketing is: (2) $V_{T}^{P}=\sum_{t} v\left(g\left(x_{t}\right)-\lambda p_{t}\right)$.

A negative per-period outcome is then coded as a loss, a positive outcome as a gain. Period-level bracketing relates to past research that provides evidence that customers often do not evaluate the joint outcomes of all choices or events (Kahneman and Tversky 1979; Thaler 1985), but instead bracket them narrowly, separately evaluating the outcomes of multiple choices (Tversky and Kahneman 1981; Read et al. 1999; Thaler 1999). Our work differs in that we extend the concept of bracketing to how consumers evaluate the decision on a stream of predetermined benefits and payments across distinct time periods. We examine whether they evaluate this decision based on its aggregate outcome or based on the outcomes of individual brackets, typically different time periods. 


\section{Hassle Costs}

The benefit customers receive from a service may vary across time periods, often due to hassle costs. Customers usually experience hassle in distinct periods, such as to set up a service, to maintain a service, or to dispose of it at the end of the contract. We define hassle costs as the non-monetary effort and inconvenience a customer incurs in setting up, maintaining or disposing of a product or service. Firms should manage hassle costs actively for three reasons. First, hassle costs are disliked by and salient to customers. Second, the firm can usually predict and manage the timing of hassle its customers' experience. Third, the firm can manage the level of hassle or, as we study in this paper, alleviate its consequences by adjusting its pricing schemes.

\section{The Effect of Hassle Costs on Decision-Making}

Period-level and contract-level bracketing lead to different choices when consumers have hassle costs. For ease of exposition, assume a two-period model and a discount rate of zero. All benefits from the product, $x_{t}$, and payments, $p_{t}$, are the same in periods 1 and 2 . Let $h_{1}$ be the hassle costs in period 1 . Assume the firm holds the total bill of the contract, $\left(p_{1}+p_{2}\right)$, constant but is indifferent to the distribution of payments over time. It can vary the price $p_{t}$ by the amount $\Delta_{t}$. This means that the firm can discount the price in the period of hassle, $p_{1}$, by $\Delta_{1}$ and increase the price in the other period, $p_{2}$, by $\Delta_{2}$. It sets $\Delta_{1}=\Delta_{2}$. If customers use contractlevel bracketing, they are indifferent to how the firm distributes payments over time with respect to hassle, since a change to the flow of payments would not affect the overall contract's value:

(3) $V_{T, d, h}^{C}=g\left(x_{1}-h_{1}\right)-\lambda\left(p_{1}-\Delta_{1}\right)+g\left(x_{2}\right)-\lambda\left(p_{2}+\Delta_{2}\right)=g\left(x_{1}-h_{1}\right)-\lambda p_{1}+g\left(x_{2}\right)-\lambda p_{2}$

This is, however, different under period-level bracketing. If monthly payments do not vary, i.e. $\Delta_{1}=\Delta_{2}=0$, consumers would code the outcome of period 1 as a lower gain than the 
outcome of period 2, or as a loss. By decreasing the price in period 1 by $\Delta_{1}$ and increasing the price in period 2 by $\Delta_{2}$, as illustrated in equation (4), the total value to the consumer increases since the marginal value per time period is lower for greater gains than for smaller gains. (4) $V_{T, d, h}^{P}=v\left(g\left(x_{1}-h_{1}\right)-\lambda\left(p_{1}-\Delta_{1}\right)\right)+v\left(g\left(x_{2}\right)-\lambda\left(p_{2}+\Delta_{2}\right)\right)$.

Therefore if there are hassle costs, the value of a contract that discounts prices in the period of hassle and charges more in the period of no hassle is higher than that of a contract with even prices in all periods. Figure 1(A) further illustrates this: The increase in period 1 value from lower payment $\Delta_{1}$, A, is greater than the decrease in period 2 value from greater payment $\Delta_{2}$, B. If the outcome of period 1 represents a loss rather than a lower gain, the effect of shifting payments across periods is even more pronounced (see Figure 1(B): The increase in period 1 value from lower payment $\Delta_{1}$, A, is greater than the decrease in period 2 value from greater payment $\Delta_{2}$, B.)

Consequently, customers who use period-level bracketing and face hassle costs prefer contracts that match periods of lower overall benefits with lower payments. This allows them to have a pattern of monetary costs that reflects the pattern of their hassle costs on a per-period level. This holds if hassle costs and lower payments occur in the second instead of the first period (in Figure 1 (A) and (B), simply reverse periods 1 and 2). Similarly, if the firm charges a fixed per-period price but discounts any one period of the contract, customers with period-level bracketing always prefer to obtain the discount in the period of hassle. Last, if customers' discount rates are positive, the preference for an early-period discount increases and the preference for a later discount decreases, but our general result still holds.

Our discussion focuses on hassle costs because of their unique importance to firms. However, shocks other than hassle costs to a customer's experience utility may have a similar 
effect. Period-level bracketing may then explain choice in other contractual settings. For example, period-level bracketing may explain why customers prefer to match the duration of a loan with the lifetime of the product that the loan finances (Hirst et al. 1994). More broadly, it can explain why New York City cabdrivers make labor decisions "one day at a time” instead of intertemporally substituting labor and leisure across multiple days (Camerer et al. 1997).

We refer to the strategy of granting lower payments in one period and recapturing the amount in other periods as contractual discounting. Customers know all prices ex ante and commit to the full schedule of prices, so a firm can use this pricing strategy to respond to customers' hassle costs. Even when the price discount occurs in the first period, contractual discounting differs from typical introductory pricing discussed by the switching costs literature (Klemperer 1995), because higher prices in later periods are contractually mandated and certain.

\section{Relationship to Prior Literature}

We next clarify how our research adds to four different but related streams of literature. First, our conceptual model relates to research on how customers react to payments and benefits that occur at different points in time (Prelec and Loewenstein 1998). This work focuses on the reciprocal interactions between the benefits ("pleasure”) and costs ("pain”) of a choice. It shows that the thought of future payment may lessen a customer's pleasure. In contrast to our work, it assumes contract-level, not period-level bracketing. As a result, customers would be indifferent between matching hassle costs with lower per-period prices and constant pricing.

Second, we contribute period-level bracketing as one motivation for why firms offer contractual discounting. It is not our objective to analyze more broadly why firms offer or how customers choose between constant pricing, early discounts or late discounts. Customers' time preferences may make them attach higher value to lower payments in early periods (Olson and 
Bailey 1981; Loewenstein 1987; Frederick et al. 2002). The promotional pull from heavily discounting one period may be larger than the pull from slightly discounting all periods (Shampanier et al. 2007). Alternatively, customers who prefer to pay the same bill every period may choose constant pricing over contractual discounting (Lambrecht and Skiera 2006). The preference for contractual discounting may also vary with whether the discount is offered early or late in a contract. The focus of our experimental design is to identify the effect of hassle costs separately from the effect of other factors.

Third, by suggesting that firms should vary prices within contracts to reflect customers' hassle costs, we introduce a new dimension into the analysis of nonlinear pricing policies. This literature traditionally focuses on how firms can use linear, two-part or three-part tariffs to implement second-degree price discrimination (Wilson 1993; Winer 2005). Two-part tariffs allow firms to price-discriminate based on customers’ average usage (e.g., Danaher 2002; Narayanan et al. 2007), whereas three-part tariffs also discriminate along customers’ usage variation (Lambrecht et al. 2007). This literature does not discuss how firms should react to hassle costs, or how period-level bracketing may affect the evaluation of long-term service contracts. Similarly, research on nonlinear pricing, the literature on dynamic prices for new durable products examines situations where prices fall over time as a response to price discrimination along customers' willingness to pay due to their product valuation, rather than to hassle costs (Nair 2008).

Fourth, our research builds on the literature on switching costs. Hassle costs and nonmonetary switching costs can both result from similar sources, such as effort invested in learning how to use a new product that would have to be replicated if the user switched to a new provider. The important distinction is that hassle costs are often independent from the intention to switch. 
They include, for example, the costs that customers undergo during regular maintenance of a service. By contrast, switching costs only include costs that customers anticipate they will have to incur if they switch providers.

The type of behavior we study is also distinct from the switching costs literature. We focus on the effect of hassle costs on customers' preferences for a sequence of prices which are set in stone by a contract. There is no uncertainty over future prices or events. By contrast, the switching costs literature investigates optimal pricing strategies if customers have monetary or non-monetary costs that make it costly to switch between sellers and if the customers anticipate that they will make further purchases at unspecified prices from the same seller that are complementary to the original purchase (Klemperer 1995; Farrell and Klemperer 2007). Empirical studies have documented that as a result of these switching costs, firms have to compensate customers with lower prices initially because customers anticipate higher prices in the future (Chen and Hitt 200; Viard 2007).

Our contribution is to demonstrate that customers prefer lower prices in the period of hassle costs, which may be any period of the contract, even if they do not anticipate higher future prices. This affects their preference for the distribution of payments over time even when the total amount is pre-determined. Our unique insight is that firms have to compensate customers with lower prices in periods of hassle costs because customers engage in period-level bracketing.

\section{FIELD EXPERIMENT}

\section{Empirical Setting}

We use data from a field experiment conducted by a web hosting provider in the UK. Web hosting providers sell web space and bandwidth for a monthly fee, allowing their customers to set up and maintain websites (see "Industry Setting” in the Online Appendix). Web hosting 
providers typically offer contracts that span multiple months. Pricing schemes vary from provider to provider, so there are few customer expectations about pricing schemes.

The web-hosting industry is characterized by high uncertainty about hassle costs, in particular about how easy it will be to set up a website. In later periods, customers typically have low or zero hassle costs. Web hosting firms are increasingly turning to search engines to acquire customers. When a customer uses a specific search term, the search engine displays the ad and charges the firm per click from the search engine’s to the firm's site.

\section{Design, Procedure and Results}

Design and procedure. This web hosting firm sells various web hosting packages to personal users and small businesses alongside domain names and offers both contractual discounting and constant monthly pricing for contracts that last three months. The firm tested which form of search advertising wording on Google was more effective in attracting serious customers. This field experiment tests how prospects react to the promise of a lack of hassle compared to an otherwise expected level of hassle; later lab experiments will test period-level bracketing when consumers expect a high level of hassle.

We expect that firms' promise of initial discounting is more attractive to customers when firms do not explicitly communicate a lack of hassle. Figure 2 displays the four advertising messages used. In the first line of the ad, the firm gave either no explicit information on the hassle of setup (“Web Host”) or explicitly communicated "no hassle" (“Web Host, No Hassle Setup”). The second line indicated the price. Ads 1 and 3 offered a monthly constant price of $£ 1.29$. Ads 2 and 4 offered contractual discounting where the first month levies a charge of $£ 0.00$ and the following months a monthly price of $£ 1.99$. Prices were set so that cumulatively, over three months, the total bill under contractual discounting would be $£ 0.11$, or $2.8 \%$, higher than 
under constant monthly pricing. We show robustness to differences in the total bill amount in the subsequent lab experiments. In the third line of the ad, " 3 mo. contracts" indicates that a contract lasts for three months. "Instant setup” indicates that webspace is allocated automatically, so that once the customer has set the website up it appears instantaneously on the Internet (see "Testing the Advertising Messages” in the Online Appendix).

Customers who clicked on any Google ad were directed to the same website of the provider, which offered all advertised hosting plans. The four ads were tested on Google in the UK over the course of seven days. Google rotated the ads automatically so that they were displayed an equal number of times. The ad messages were associated with 14 different search terms (Table 1). There was large variation in both the number of impressions (the number of web searchers who saw the ad because they used that search term), and the click-through rates (the number of web searchers who, having used that search term, clicked on the ad). Over 79,000 web searchers were exposed to the different randomized treatments. We checked that there was no difference in how technical the search terms were that users used to reach the website by condition. There was no statistical difference between the two hassle-conditions (p-value $=0.87$ ) or between the two pricing-conditions ( $\mathrm{p}$-value=0.15).

Our conceptual framework predicts that, for a customer who anticipates low hassle cost, the pattern of prices with initial discounts does not mirror the pattern of hassle costs. Such a customer should be less likely to be attracted by a contract that offers contractual discounting than a customer who views an ad that does not provide information about hassle costs. We therefore expect ads that advertise both separately to perform significantly better than the ad that jointly advertises “no hassle” and contractual discounting or the ad that advertises neither. 
We evaluate the empirical data on three levels. First, we analyze how likely customers that viewed the different ads were to click through to the firm's website. Since Google does not provide information on the success of each ad variation by keyword, but only in aggregate, we are not able to include keywords as controls in our click-through analysis. Second, we analyze subsequent browsing behavior once customers arrived on the website. Third, we stratify our analysis of browsing behavior by what search term people used to reach the website.

Results based on click-through rates. Table 2 displays the click-through rates (CTR) for each of the ad variations from Figure 2. The least successful ad was the one that combined both a message of "no hassle" and contractual discounting (CTR 0.40\%). In line with our expectation, the raw mean CTR suggest that the most successful ads were the ads that offered either contractual discounting (CTR 0.53\%) or "no hassle" (CTR 0.53\%).

Table 3 displays a probit specification that compares the performance of the ads in order to evaluate the statistical differences between the rates displayed in Table 3 . The dependent variable is whether a visitor to Google who saw the ad clicked through on the ad. The base condition is the worst-performing ad ("no hassle" and contractual discounting).

As expected, the analysis shows that relative to the baseline ad that offers both "no hassle" and contractual discounting, it was more effective to either advertise a lack of hassle or to advertise contractual discounting in isolation $(\mathrm{p}<0.05)$. The insignificant coefficient on "neither mentioned" suggests that while the messages were effective in isolation, when combined these marketing messages performed in a way which was statistically similar to offering neither. This is in line with our conceptual framework. Ads that imply that the pattern of monetary costs reflects the pattern of lower benefits due to hassle costs over time perform better than ads which do not. The second and third columns show different specifications that control in turn for the 
average position that the ad was displayed upon and the day of the week. This serves as a randomization check. As expected, neither type of control changes the estimates significantly.

Results based on browsing behavior. The prior analysis does not tell us whether these ads attracted the right kind of customer to the website. On average, the firm paid over $\$ 5$ to attract a customer to its site, so it wanted to ensure that this was not a casual customer who left quickly but someone who would interact with the site. Using actual orders is difficult, since customers typically do not order on their first visit. The extent of visitors' browsing on a website indicates how strongly they engage with the website. As discussed by Bucklin and Sismeiro 2003 and Montgomery et al. 2004, measures of click-stream browsing are a meaningful measure of customer engagement and a predictor of repeat visits and the likelihood of purchase.

To evaluate the effect of the ad variations on attracting customers who would engage with the website, we use web server log file data tracking which customers arrived on their website from Google using which ad. From the full set of customers that arrive at the provider's site from one of the four ads, we remove 39 observations from automated "bots” and "spiders.” This leaves us with 448 individuals who arrived at the website from each of the four ads. ${ }^{1}$ As our dependent measure, we use the number of webpages each customer browsed. We recognize that this measures early consumer interest in the website and product, as opposed to the actual final stages of purchase behavior. It also may be an imperfect measure if browsing is correlated to experience. In our lab experiments, we confirm that our result carries through to more direct measures of purchase. We use a Poisson specification to examine how the number of webpages

1 The number of individuals who the log files identified as having clicked on an ad was more than Google reported, likely because Google does not report statistics for clicks that their click-fraud program identified as potentially fraudulent. Since Google does not share this data, we have no means of identifying which these potentially fraudulent clicks are and cannot eliminate these observations in the analysis of click-throughs. 
each customer browsed depended on whether the ad that had attracted her to the website offered a contractual discount, mentioned "no hassle", or both. ${ }^{2}$

Most customers had been attracted by an ad that neither offered contractual discounting nor mentioned "no hassle.” We take this as the base condition. This contrasts with Table 3, where the base condition was the ad which combined "no hassle" and contractual discounting. Again, advertising "no hassle” and contractual discounting separately allows monetary costs to reflect the pattern of non-monetary costs and should be more effective at attracting serious customers, i.e., customers that browse more, than advertising both jointly. Therefore, we expect to find a positive effect of advertising either "no hassle" or contractual discounting separately.

In line with our expectations, the results show that advertising "no hassle" on the website significantly increases the probability of customers browsing extensively (column (1), Table 4). The positive and highly significant coefficient for contractual discounting confirms that advertising a pricing scheme with contractual discounting does attract more customers, underlining that, on average, customers prefer contractual discounting. Our results demonstrate a negative interaction effect between mentioning "no hassle" and offering contractual discounting (-0.357) which largely offsets the positive effects of advertising contractual discounting (0.390), indicating that when both messages are combined the overall effect is significantly weakened. Joint advertising of both messages does not allow customers to match the pattern of their monetary and non-monetary costs. Put differently, customers gain less additional value from easy setup when contractual discounting is available.

Running a separate regression that does not include the interaction effect, as is displayed in column (2), suggests that contractual discounting increased web browsing by only $21 \%$, rather

2 Our results are similar if we use a linear specification. 
than the 39\% that we find when including the interaction term in column (1). This suggests that not accounting for the effect of hassle costs can lead firms to underestimate the effect of contractual discounting on choice.

Validation of results by search terms. To confirm that the underlying mechanism driving our results relates to customers' anticipation of hassle, we stratify our results by whether or not the customer is likely to anticipate hassle. As our shifter, we use data indicating the customer's prior expertise in web hosting. Web hosting is a fairly new industry, so many customers have limited to no purchasing experience. However, customers with high technical expertise will always find it easier than customers with low technical expertise to set up websites.

The keywords that the firm paid to advertise in association with do not perfectly map onto actual search terms. Any search which contains the word "hosting", like "java script hosting," would lead to the user seeing the firm's advertising. The click-stream data contained a complete set of records of search terms used to reach that particular search page. Table 5 summarizes the phrases we used to identify technical searchers and provides some summary statistics. We stratify our results by whether a technical or a non-technical search term was used. Technical searchers should anticipate low hassle costs independently of whether the ad includes a message on hassle costs. If they wish their payments to mirror the pattern of their hassle costs per period, technical searchers should value contractual discounting less than non-technical searchers. In addition, advertising "no hassle” should not significantly affect behavior. Last, the interaction between both messages should be insignificant.

The results for non-technical search terms are similar to those obtained for the full sample (columns (3) and (4), Table 5). As expected, the message of “no hassle” did not significantly increase acquisition of customers who used technical search terms and, because of their good 
technical knowledge, were likely to expect low hassle costs independently of the advertising message. Combining a message of "no hassle” and contractual discounting also had no significant effect. In line with our expectation, the effect of advertising contractual discounting separately is lower and less significant than for non-technical searchers. The fact that contractual discounting still has a positive effect indicates that in addition to reflecting the pattern of their hassle costs, customers also prefer contractual discounting for other reasons.

Summary. Our field experiment provides evidence that customers prefer contracts that match periods of lower benefits due to hassle costs with lower payments. This indicates they use period-level bracketing. It also demonstrates that firms' use of discounts within a contract is more attractive to customers when firms do not explicitly reassure customers about hassle costs.

The field experiment has three limitations. First, we measure how effective the ad is in attracting potential customers, but not choices. Second, we do not test how potential customers react when the firm explicitly communicates high hassle rather than merely a lack of hassle. Third, we cannot rule out that other factors affected our results. For example, a potential signaling effect of a zero price in the first period (Shampanier et al. 2007) might affect choices differently across conditions. Greater discount rates of prospects in the hassle condition could also lead to the effect we observe (Zauberman et al. 2009). Next, in a series of five lab experiments, we address these limitations and broaden our findings. The Online Appendix reports four additional lab experiments that support our findings. ${ }^{3}$

3 The first lab experiment in the Online Appendix is set in a similar setting as the field experiment, web hosting, and extends the findings of the field experiment to actual choice of pricing plans, rather than focusing on attracting potential customers as the field experiment does. 


\section{LAB EXPERIMENTS}

\section{Overview of lab experiments}

In five lab experiments, we evaluate consumers’ choices of pricing plans or discounts when firms signal that consumers will face a high level of hassle. We show that consumer preferences to match the timing of a discount with the period of hassle, hold whether hassle costs arise at the beginning, during, or at the end of a firm's and consumer's contractual relationship. We also show the effect holds whether consumers choose between pricing plans or the timing of a discount. Table 6 summarizes our lab experiments.

Lab experiment 1 focuses on hassle at the beginning of a contract. It sets a clear end to the contract to eliminate the possibility that subjects' choices relate to their expectation of how long they will use the service. It rules out confounds such as discount rates, the perception of the firm's overall quality and of its pricing plans. Lab experiment 2 tests whether when hassle arises during the contractual relationship, consumers are more likely to prefer a later discount in the month of hassle.

Lab experiment 3 provides direct support for period-level bracketing by testing whether consumers are more likely to choose a discount if the billing bracket encompasses the timing of the hassle than if it does not. Similarly, lab experiment 4 tests whether consumers' sensitivity to a fixed level of hassle cost diminishes when hassle occurs during a longer bracket. In long brackets, the relative size of hassle costs is smaller in comparison to benefits than in short brackets. Lab experiment 5 tests whether our findings extent to where hassle costs arise in the last period of a contract (see also lab experiment A-4 in the Online Appendix) and when consumers face large monetary expenditures. 


\section{Lab Experiment 1: Hassle in Setup, High Level of Hassle}

Objective. We address four points. First, we define the duration of and a clear end point to the contract. This eliminates the possibilities that subjects' choices relate to their expectation of how long they will use the service, or that some subjects assume they can terminate the contract early. Second, we explicitly communicate a high level of hassle, rather than comparing a "no hassle” setting to a condition where hassle costs are not manipulated. Third, we rule out as confounds discount rates, subjects' perception of the firm's overall quality and of the firm's pricing plans. This may be relevant since subjects might find it unconvincing that a firm's offering is good on two dimensions. Offering a low price in the initial period despite the absence of hassle costs could be perceived as a "hard sell” (Chernev and Carpenter 2001). We also set the price in the first period to be greater than zero to eliminate a "zero price" signaling effect (Shampanier et al. 2007). Last, we extend our results to a setting where subjects choose between the timing of a discount rather than between two pricing plans. Our objective is to show that subjects with higher anticipated hassle costs are more likely to prefer a discount in the month of hassle.

Design and procedure. Subjects are told to imagine that they are working as a freelancer and moving to a new city for six months. During this time, they will be getting fiber optic service (FiOS). The contract will end after six months, after which they will return home where the service is not available. Subjects cannot end the contract early.

We manipulate the hassle of installation. In the no-hassle condition, subjects are told: "The company will switch on FiOS in two days from now. No further action from your side is required and a technician does not need to come to your home.” In the hassle condition, subjects are told: "They cannot simply switch on FiOS. Rather, a technician needs to come to your home 
to install it. The technician will visit the day after tomorrow between 8 am and $6 \mathrm{pm}$. During this day you have to stay at home from 8 am to 6 pm and cannot go to work. You will have to make up for the lost work hours on other days.” Subjects are then asked to imagine they are looking at the FiOS pricing plans and to choose one pricing plan. All subjects are presented with two plans. One plan charges $\$ 41$ per month in months 1 to 6 and one plan charges $\$ 6$ in the first month and then $\$ 48$ in each of months 2 to 6 .

Finally, subjects answer questions that relate to the scenario. We ask subjects to indicate on a 7-point scale how much hassle they think it will take to set up FiOS with this company (1: “no hassle”, 7: "a lot of hassle”). We measure how likely they think the company is to offer each pricing plan (1: "very unlikely”, 7: "very likely”), whether they find the pricing plans confusing (1: “very confusing”, 7: “not at all confusing”) and how good overall the company is in providing FiOS service (1: “very bad”, 7: “very good”).

We measure subjects' discount rates in two ways. First, using the specific context of FiOS, we tell subjects that the company offers them a discount voucher of $\$ 30$ for their service that is valid in month 2. Subjects are then asked how much they would want to be compensated if they would only be able to redeem the discount three months from now. Second, we measure discount rates independently of the specific context. Building on prior research (Zauberman et al. 2009), we tell subjects to imagine they have received a $\$ 75$ gift certificate and then ask them to indicate how much they would need to be paid to delay using it for 3 months. We repeat the same question with a $12-$ month delay. ${ }^{4}$

We expect customers whose service is automatically connected to be less likely to choose contractual discounting than customers who have to wait for one day. This is based on our theory

$4 \quad$ We calculate the discount rate $r$ as follows $r=\left[\ln \left(Y_{t+k} / Y_{t}\right)\right] / k . Y_{t}$ is the amount at the initial period, $k$ is the time expressed in years and $Y_{t+k}$ is the total amount in $\mathrm{k}$ (Zauberman et al. 2009). 
that customers engage in period-level bracketing and prefer the pattern of their monetary costs to reflect the pattern of their hassle costs over time. We expect this effect to persist even when accounting for other factors like customer discount rates.

83 subjects were recruited online through the Amazon Mechanical Turk ${ }^{5}$ and randomly assigned to conditions (41 responses for the no-hassle condition, 42 for the hassle-condition).

Results. Perceived hassle is significantly lower in the no-hassle condition than in the hassle condition (2.561 vs. 5.095, $\mathrm{p}<0.001)$. We conclude that the manipulation successfully induced the perception of hassle. As hypothesized, the probability of choosing contractual discounting is significantly greater if subjects have to wait for the technician. In the no-hassle condition, $39.0 \%$ of subjects choose contractual discounting, and in the hassle condition $61.9 \%$ $(\mathrm{p}=0.037)$. The logit model in column (1), Table 7 confirms the result. Column (2) uses the perceived level of hassle as an independent variable and confirms that indeed the level of hassle does affect pricing plan choice.

Subjects evaluate the company to be better in providing the service in the no-hassle condition than in the hassle condition (5.024 vs. 4.381, $\mathrm{p}=0.009)$. Subjects rate neither of the plans as unlikely to be offered by the company or as confusing. They find it slightly more likely that the firm offers a constant plan than contractual discounting (5.204 vs. 4.567, $\mathrm{p}=0.014$ ) but there are no differences between conditions in how likely each plan is perceived to be offered (constant pricing: 5.317 vs. 5.095, $\mathrm{p}=0.527$; contractual discounting: 4.439 vs. 4.690 , $\mathrm{p}=0.522$ ). This indicates that subjects do not find offering contractual discounting a "hard sell" in either condition. They rate the constant plan as closer to "not at all confusing” (6.229 vs. 4.976,

5 For details on the Mechanical Turk, see Goodman et al. 2010. This study and all following studies that were conducted on the Mechanical Turk restricted participation to people who were in the US. 
$\mathrm{p}<0.001$ ). None of the control variables significantly affect choice of the pricing plans (columns (3) and (4), Table 7).

We test whether subjects' discount rates affect the choice of contractual discounting. None of the discount rates are significantly different across conditions. The discount rate measured in the context of FiOS does not affect choice (column (5), Table 7; see subsection “Testing for Differences in Discount Rates” in the Online Appendix for a summary of discount rates in lab experiments 1 to 5). The context-independent discount rate for 3 months is greater than for 12 months, which indicates hyperbolic discounting (1.483 vs. $0.603, \mathrm{p}<0.001)$. The 3month discount rate (but not the 12-month discount rate) significantly affects plan choice but that does not mitigate the effect of the no-hassle condition (columns (6) and (7), Table 7).

We conclude that customers are substantially more likely to prefer contractual discounting if setup involves greater hassle. Customers prefer their monetary costs to reflect the pattern of their perceived hassle costs over time, even when the price in the initial period exceeds zero. The results also show that firms can manipulate preferences by communicating different degrees of hassle. They rule out as confounds the expected duration of the contract, customers' perception of the firm's overall quality, their perception of pricing plans or their discount rates.

\section{Lab Experiment 2: Hassle during contract}

Objective. This experiment extends our results to hassle during a contract. In addition, we vary the source of hassle. While in the previous experiment the source of hassle lay in the effort individuals needed to invest, hassle now arises from inconvenience. We aim to show that greater hassle during a contract leads consumers to prefer to time a discount in the period of hassle.

Design and procedure. Subjects are told to imagine that they are renting a home and not planning to move. In the no-hassle condition, subjects are told "In three months from now, the 
water company will carry out repair work of your neighbor's water pipes. You will not be inconvenienced since it only concerns the shared border of both houses.” In the hassle condition subjects are told "In three months from now, the water company will carry out repair work of the water pipes of your house. You will not be charged for the repair work. At a great inconvenience to you, for two weeks, workers will continuously require access to your home and you will need to arrange for someone to be there to let them in and out of your house throughout the day.” In both conditions, subjects then choose between a discount to their water bill of $\$ 30$ this month or a discount of \$30 in month 3.

Similarly to the previous experiment, subjects then answer questions regarding the scenario. We measure how much hassle subjects think the repair work will involve for them and how good they think the company is overall. Subjects are asked whether they think it is likely that the company offers each of the discounts, how likely they think it is that the repair work involves the scenario described above and how likely they think it is that the repair work will be completed successfully. To measure context-specific discount rates, we tell subjects to imagine that the company sent a discount voucher of $\$ 30$ valid this month. We ask how much they would need to be paid to consider delaying the use of it by 3 and 6 months. We measure 3- and 6-month context-independent discount rates, as we did in lab experiment 1.

If indeed period-level bracketing leads to the choice of a discount in the period of hassle, the share of customers that chooses the discount in the month of repair work should be greater when customers have greater hassle costs, i.e. in the no-hassle condition.

80 subjects were recruited through the Mechanical Turk and randomly assigned to one of the conditions (43 responses for the no-hassle condition, 37 for the hassle condition). 
Results. We successfully manipulated perceived hassle across conditions (2.163 vs. 6.162, $\mathrm{p}<0.001$ ). Our results confirm that subjects are significantly more likely to choose the discount in the replacement month if the replacement involves greater hassle (20.9\% vs. $45.9 \%$, $\mathrm{p}=0.017$ and columns (1) and (2), Table 8). We check whether these results are robust to controls. Subjects in the no-hassle condition rate the company as better than subjects in the hassle condition ( 5.233 vs. $3.595, \mathrm{p}=0.001$ ). Subjects do not think that the repair work is more likely to be successful in either of the conditions (5.558 vs. 5.189, $\mathrm{p}=0.200$ ) and also do not think that either scenario is more likely to occur ( 4.070 vs. $3.513, \mathrm{p}=0.151)$. In both conditions, subjects' rating of how likely the company is to offer the discount is similar for the early discount (3.465 vs. 3.486, $\mathrm{p}=0.962$ ) but in the hassle condition they find it more likely that a firm will offer a discount in the third month (3.721 vs. 5.000, $\mathrm{p}=0.005)$. None of the control variables affect the results (columns (3) and (4)). Similarly, discount rates do not differ significantly across conditions. We find no significant effect of 3-month context-specific discount rates (column (5)), but subjects with higher 3-month context-independent discount rates are less likely to choose the later discount (column (6)). This does not, however, mitigate the effect of greater hassle. Neither of the 6-month discount rates significantly affects results.

The results confirm that period-level bracketing motivates customers to choose a discount at the time of hassle and as a consequence forego earlier discounts of a greater net present value. This is also the case if consumers face hassle during instead of at the beginning of their contract (see also lab experiments A-2 and A-3 in the Online Appendix).

\section{Lab Experiment 3: Hassle Falling Inside vs. Outside a Bracket}

Objective. We test whether period-level bracketing holds by varying the length of the evaluation bracket, for example to be a week, a month, a quarter or a year. If we hold constant 
the flow of benefits and costs but vary the length of the bracket, whether or not a discount falls into the period of hassle then depends on the length of the bracket. A short bracket may end before hassle occurs whereas a long bracket may run on to include the time of hassle. We predict that consumers should have a greater preference for a later discount if that later discount falls into the same bracket in which consumers face hassle than if it does not fall into the same bracket as hassle. Only if both fall into the same bracket, will choosing the later discount allow consumers to match benefits and payments on a period-level. We aim to show that consumers who choose between an early and a late discount are more likely to choose a later discount if the payment bracket into which the late discount falls, also covers the hassle.

Design and procedure. This study has a 2 x 2 design. We vary hassle (no hassle, hassle) and the length of the bracket (weekly, monthly). Subjects are asked to imagine they are taking the train to work every day for 20 minutes. They have pre-committed to a yearly train pass. In the weekly conditions subjects are told they pay a flat fee every week, in the monthly conditions the flat fee is paid every month. In the hassle conditions subjects are told the railway company has announced track replacement works in 8 weeks from now. During week 8 they will use a bus replacement service and it will take 90 minutes to get to work.

Subjects are asked to imagine they have received a discount coupon from the railway company of $\$ 10$. In the weekly conditions they can apply it to their next weekly pass or use it in 5 weeks from now. In the monthly conditions they can apply it to their next monthly pass next week (for weeks 1 to 4 ) or in the following month (for weeks 5 - 8).

To make it plausible to all subjects that the firm would offer a discount in week 5 , they are told that week 5 is the $150^{\text {th }}$ birthday of the internal combustion engine. Given the complexity of the scenario, subjects in the weekly hassle condition, are reminded that neither of the discounts 
covers the time of service disruption. In the monthly hassle condition, they are reminded that the discount in the following month will cover the time of service disruption. Subjects then choose when to apply the discount.

We measure how much hassle subjects think it will be to get to work in week 8 and how good they think the company is overall. Subjects are asked whether they think it is likely that the company offers each of the discounts. To measure context-specific discount rates we ask subjects to imagine the company sent a discount voucher valid this month. We then ask how much they would need to be paid to delay using the discount by one and by six months. Our measure of context-independent discount rates for one and six months is similar to lab experiment 1.

If the wish to better match the timing of hassle with the timing of the discounts leads customers to choose a later discount, customers should have a greater preference for the late discount in the monthly hassle condition than in the weekly hassle condition. In the monthly but not in the weekly condition, the discount is applied to a period that covers the time of hassle.

197 subjects were recruited through the Mechanical Turk and randomly assigned to a condition (50 responses for the weekly no-hassle condition, 51 for the weekly hassle condition, 46 for the monthly no-hassle condition, 50 for the monthly hassle condition).

Results. The perceived level of hassle varies significantly between the no-hassle and hassle conditions (2.448 vs. 6.020, $\mathrm{p}<0.001$ ). Importantly, in the monthly setting subjects are significantly more likely to choose the later discount when there is hassle than when there is no hassle $(17.3 \%$ vs. $44.0 \%, \mathrm{p}=0.005)$. When the bracket does not cover the time of hassle as in the weekly condition, subjects do not prefer a later discount ( $17.6 \%$ vs. $24.0 \%$, $\mathrm{p}=0.432)$. Column (1) in Table 9 confirms this. Subjects rate the company as better when there is no hassle than when they face hassle (5.323 vs. 4.802, $\mathrm{p}=0.003$ ). In both settings, subjects' rating of how likely 
the company is to offer the discount is similar for the early discount ( 4.760 vs. $4.861, \mathrm{p}=0.697$ ) but in the hassle conditions they find it more likely that a firm will offer a later discount (5.297 vs. 4.708, $\mathrm{p}=0.012$ ). These control variables do not affect the results (columns (2) and (3)). Similarly, we find no significant effect of discount rates (column (4)). The linear probability model in column (5) confirms the results.

Our theory suggests that consumers want to match the timing of benefits and payments on a per-period level since they bracket outcomes by periods. This experiment demonstrates that it is indeed important that benefits and payments fall into the same bracket. It shows that even if we hold constant the time of hassle and the timing of a discount, consumers like a later discount significantly better if both hassle and discount fall into the same bracket than if they fall into separate brackets. This provides strong additional evidence for period-level bracketing.

\section{Lab Experiment 4: Short vs. Long Brackets}

Objective. Holding constant the flow of benefits and hassle costs, consumers should be less sensitive to hassle costs when they face hassle during a longer bracket with greater total benefits, compared to facing the same amount of hassle in a shorter bracket with lower total benefits. The reason is that the same amount of hassle is larger relative to expected benefits in a shorter bracket than in a longer bracket. Therefore, decreasing payments in the period of hassle should have a greater value if the bracket is shorter. Our aim is to test whether consumers have a greater preference for a discount that matches the timing of hassle when hassle occurs in a shorter bracket with lower overall benefits than in a longer bracket.

Design and procedure. This study has a 2 x 2 design. We vary hassle (no hassle, hassle) and the length of the bracket (weekly, quarterly). Subjects are asked to imagine they work out at a health club every day before work for 1 hour. They have pre-committed to a yearly 
membership. In the weekly conditions they are told they pay a flat fee every week, in the quarterly conditions it is paid every quarter. In the hassle conditions subjects are told the health club has announced repairs to the shower facility for week 13 which means they will have to drive home after their work out in order to shower. They are told this represents $50 \%$ of the time they exercise that week (in the weekly hassle condition), or $4 \%$ of the time they exercise that quarter (in the quarterly hassle condition). Subjects are told they receive a discount of $\$ 15$ from the health club. In the weekly conditions, they choose between applying it to week 1 or 13 . In the quarterly conditions, they choose between applying it to quarter 1 or 2 .

We also measure how much hassle subjects think the repairs will cause for them. Subjects are asked whether they think it is likely that the company offers each of the discounts. We also measure context-specific and context-independent discount rates for three and six months.

We expect that customers have a greater preference for the late discount in the weekly than in the quarterly hassle condition, since the discount at the time of hassle will be valued more in a period of lower benefits.

409 subjects were recruited through the Mechanical Turk and randomly assigned to a condition (109 responses for the weekly no-hassle condition 1, 98 for the weekly hassle condition, 102 for the quarterly no-hassle condition, 100 for the quarterly hassle condition).

Results. The perceived level of hassle varies significantly between the no-hassle and hassle conditions ( 3.177 vs. $5.104, \mathrm{p}<0.001$ ). It is not significantly different between the two hassle conditions (5.092 vs. 5.117, $\mathrm{p}=0.902$ ). Importantly, in the weekly setting subjects are significantly more likely to choose the later discount when there is hassle than when there is no hassle $(19.4 \%$ vs. $50.5 \%, \mathrm{p}<0.001)$. However, in the quarterly condition subjects are not 
significantly more likely to prefer a later discount (31.0\% vs. $35.2 \%, \mathrm{p}=0.517)$. The difference between the weekly and the quarterly hassle condition is significant ( $\mathrm{p}=0.026)$. Column (1) in Table 10 confirms this. In both settings, subjects' rating of how likely the company is to offer the discount is similar for the early discount (4.479 vs. 4.184, $\mathrm{p}=0.116)$, but in the hassle conditions they find it more likely that a firm will offer a later discount (4.157 vs. 4.972, $\mathrm{p}<0.001)$. Our results are robust to including these control variables (columns (2)). We find no significant effect of discount rates (column (3)). The linear probability model in column (4) confirms the results.

We conclude that indeed, given a fixed flow of benefits and hassle costs, consumers have a greater preference for a later discount if the bracket is shorter and the value of a discount is greater relative to the overall benefits consumers receive in that period.

\section{Lab experiment 5: Hassle at End of Contract, High Monetary Values}

Objective. This experiment demonstrates that the preference for matching benefits and payments persists when hassle costs occur at the end of the contract. In addition, we show that the effect holds for larger amounts than those that households typically spend on their service contracts but which are not unusual for a setting such as vacation rentals. Our experiments so far either held the total bill constant under both pricing plans, or charged slightly more under contractual discounting, but we have not varied these within the same experiment. We now test whether the preference for matching lower benefits with lower payments within periods holds if contractual discounting is more or less expensive than constant pricing. We aim to show that it will hold when the total bill under contractual discounting is greater, since the behavioral mechanism that we posit is separate from the prices billed. When the bill under contractual discounting is lower, it is possible that the attractiveness of a lower bill dominates hassle considerations both when there is hassle and no hassle. 
Design and procedure. This study has a 2 x 3 design. We vary hassle (no hassle, hassle) and total bill under constant pricing and contractual discounting (same, contractual discounting more expensive, contractual discounting less expensive). We told subjects to imagine they are about to rent a remote house with a garden, pool and hot tub for a vacation in Mexico. They are going alone, paying for the vacation and putting down a \$1000 down-payment to the management company. Subjects are instructed:

- No-Hassle Conditions: Before you leave you will hand over the keys to the management company. The management company will thoroughly clean the property including the bedroom, a large living room, kitchen, and a large bathroom. They will also mow the lawn and clean the pool and the hot tub. The management company will inspect the house before you leave but has never retained the down-payment since cleaning services are provided by their staff after you leave.

- Hassle Conditions: Before you leave you will have to thoroughly clean the property including the bedroom, a large living room, kitchen, and a large bathroom. You will also have to mow the lawn and clean the pool and the hot tub. This will mean several days of work during your last week of vacation. You will need to hand over the keys to the management company. They will inspect the house before you leave and will retain the down-payment if the property is not properly cleaned.

- No-Hassle Conditions: On your last day you will be responsible for handing over the keys to the management company.

- Hassle Conditions: You will be solely responsible for cleaning the house, including the garden, the pool and the hot tub, and handing over the keys. Since it’s in a remote place, you are also not able to hire cleaning staff.

Subjects are then asked to choose between two different pricing schemes. In the nohassle conditions they are asked to keep in mind that the management company takes care of cleaning the house, garden, pool and hot tub. In the hassle conditions they are told that cleaning the house, garden, pool and hot tub will take a significant amount of time in the last week]. In the same-bill conditions both plans charge the same total bill. In the lower-bill conditions the total 
bill under contractual discounting is less than under constant pricing. In the higher-bill conditions the total bill under contractual discounting is greater than under constant pricing. Table 11 summarizes the pricing plans across conditions.

We measure the hassle subjects think it will take to clean the property and hand over the keys. We ask subjects whether they think that overall the vacation will be enjoyable (1: "not at all enjoyable”, 7: “very enjoyable”) and whether they think the management company is likely to return the full down-payment. We also ask when they assumed they would be paying for the vacation (pay the full amount before or at the start of the vacation, pay the weekly rate at the beginning of each week, pay the weekly rate at the end of each week, pay the full amount at the end of the vacation). As before, we measure 3- and 12-month context-independent discount rates.

311 subjects were recruited through the Mechanical Turk and randomly assigned to a condition (52 responses for the same-bill no-hassle condition, 52 responses for the lower-bill nohassle condition , 52 for the higher-bill no-hassle condition, 56 for the same-bill hassle condition, 45 for the lower-bill no-hassle condition, 53 for the higher-bill hassle condition).

Results. The perceived hassle is significantly higher in the hassle conditions than in the no-hassle conditions (3.058 vs. 5.382, $\mathrm{p}<0.001$ ). As hypothesized, the probability of choosing contractual discounting is significantly greater in the hassle conditions (Table 12). This effect is strongest when both plans have the same total bill. It is marginally significant when contractual discounting is more expensive. When contractual discounting is less expensive, the share of subjects choosing contractual discounting is not significantly different across the hassle and the no-hassle conditions as the majority of customers prefer the less expensive contractual discounting, independently of the level of hassle. 
A logit model confirms that hassle leads to a significantly greater probability of choosing contractual discounting (columns (1) and (2), Table 13). Subjects are more (less) likely to choose contractual discounting if the total bill under contractual discounting is lower (greater) than under constant pricing. We include interactions between the dummies for the hassle condition and the price levels in column (3) and control variables in columns (4), (5) and (6). Column (7) is a linear probability model of column (6). Hassle and a lower bill under contractual discounting both increase the probability of choosing contractual discounting. A greater bill under contractual discounting has a marginally negative effect. The interactions between hassle and a different bill under contractual discounting are insignificant: the additivity of either effect is not significantly weakened or strengthened by the presence of both hassle and a different total bill. Neither the expected likelihood of receiving the down-payment nor subjects' enjoyment of the vacation mitigate the effect of hassle. ${ }^{6}$ The results are robust to when subjects assume they would pay for the vacation. ${ }^{7}$ As expected, discount rates do not significantly affect plan choice.

The results illustrate that the wish to match the timing of benefits and payments persists when hassle occurs in the last period and when prices are much higher than for typical service contracts. When the bill is higher under contractual discounting the overall preference for contractual discounting is of course lower, but subjects still have a marginally greater preference for contractual discounting. When the bill under contractual discounting is lower, subjects have a clear preference for contractual discounting, independently of their level of hassle.

\footnotetext{
$6 \quad$ Subjects in the no-hassle conditions rate the likelihood of receiving the down-payment and their enjoyment of the vacation slightly higher (return down-payment 5.383 vs. 4.408, $\mathrm{p}=0.000$; enjoyment 5.896 vs. 4.764, $\mathrm{p}=0.000)$.

$7 \quad 37.9 \%$ assume they would pay the full amount before or at the start of the vacation, 37.9\% assume they would pay the weekly rate at the beginning of each week, $17.4 \%$ assume they would pay the weekly rate at the end of each week and $6.8 \%$ assume they would pay the full amount at the end of the vacation.
} 


\section{CONCLUSION AND IMPLICATIONS}

Many customers subscribe to long-term contracts for services. We suggest that customers evaluate multi-period service contracts using period-level bracketing. The total value of the contract is the sum of the distinct per-period losses and gains.

We demonstrate that under period-level bracketing, customers are not indifferent to the distribution of net discounted payments and benefits over time. This is important if customers' value from a contract varies across periods. One important source of such variation is hassle costs. Hassle costs arise in setting up a service, maintaining a service or ending a contract. Therefore firms can time payments within a contract to acquire and retain customers who may otherwise be deterred by hassle costs.

Across a field experiment and five lab experiments, we demonstrate that customers prefer payments for the service to reflect the pattern of their hassle costs over time. High hassle costs make pricing schemes with discounts in the period of hassle more attractive. This is true independently of whether hassle occurs in the first period of a contract, in an intermediate period or in the last period. Customers are even willing to allocate a discount to a later period, if this allows them to match higher expected hassle costs with lower payments in individual time periods. Our experiments rule out alternative explanations, including hyperbolic discounting, a potential signaling effect of a zero-price in the first period, a preference for simple versus complex schemes, the expected relationship length and the possibility that customers find it a "hard sell” for a firm to offer a low price jointly with low hassle.

Our findings have implications for marketing research. Crucially, our results show that period-level bracketing matters in decision-making. While our work focuses on the effect of hassle costs, period-level bracketing may affect choices when variation in benefits arises from 
sources other than hassle costs. Our findings also suggest that price responsiveness is correlated with perceived hassle costs, so researchers modeling decisions (for example, adoption decisions) that involve hassle costs should allow for an interaction of hassle costs and price responsiveness.

Our results have implications for managers: First, when introducing a new service, firms should offer a pricing plan that reflects the anticipated timing of hassle costs. Conversations with managers suggest that they use initial discounts mainly to grab the attention of casual browsers, rather than as part of a strategy to compensate customers for hassle costs. However, our research suggests that it may be wiser to target initial discounts at inexperienced users who are more likely to have hassle costs. Similarly, firms should target initial discounts towards products that consumers perceive as having high hassle costs. Second, our findings are not limited to initial periods, but extend to any period where customers bear hassle costs. Firms that anticipate hassle in a future month should offer customers a specific discount for that month. Pre-emptive or posthoc compensation for hassle costs are likely less effective than compensation at the time of hassle costs. Since on average, customers prefer "hassle discounts” over earlier discounts that have a greater net present value, a firm may further benefit from granting discounts that have a lower net present value but are of greater value to its customers. 


\section{REFERENCES}

Benartzi, Shlomo and Richard H. Thaler (1995), "Myopic Loss Aversion and the Equity Premium Puzzle," Quarterly Journal of Economics, 110 (1), 73-92.

Benartzi, Shlomo and Richard H. Thaler (1999), "Risk Aversion or Myopia? Choices in Repeated Gambles and Retirement Investments," Management Science, 45 (3), 364-81.

Bucklin, Randolph E. and Catarina Sismeiro (2003), "A Model of Web Site Browsing Behavior Estimated on Clickstream Data," Journal of Marketing Research, 40 (3), 249-67.

Camerer, Colin, Linda Babcock, George Loewenstein, and Richard H. Thaler (1997), "Labor Supply of New York City Cabdrivers: One Day at a Time," Quarterly Journal of Economics, 112 (2), 407-41.

Chernev, Alexander and Gregory S. Carpenter (2001), "The Role of Market Efficiency Intuitions in Consumer Choice: A Case of Compensatory Inferences," Journal of Marketing Research, 38, 349-61.

Danaher, Peter J. (2002), "Optimal Pricing of New Subscription Services: Analysis of a Market Experiment," Marketing Science, 21 (2), 119-38.

Farrell, Joseph and Paul Klemperer (2007), "Coordination and Lock-In: Competition with Switching Costs and Network Effects," in Handbook of Industrial Organization, M. Armstrong and R. Porter, Eds. Vol. Chapter 31: eds. Amsterdam: North Holland.

Frederick, Shane, George F. Loewenstein, and T. O'Donoghue (2002), "Time Discounting and Time Preference: A Critical Review," Journal of Economic Literature.

Goodman, Joseph K., Cynthia E. Cryder, and Amar Cheema (2010), "Data Collection in a Flat World: Accelerating Consumer Behavior Research by Using Mechanical Turk," Working paper.

Hirst, D. Eric, Edward J. Joyce, and Michael S. Schadewald (1994), "Mental Accounting and Outcome Contiguity in Consumer-Borrowing Decisions," Organizational Behavior and Human Decision Processes, 58, 136-52.

Kahneman, Daniel and Amos Tversky (1979), "Prospect Theory: An Analysis of Decision under Risk," Econometrica, 47 (2), 263-91.

Klemperer, Paul (1995), "Competition When Consumers Have Switching Costs: An Overview with Applications to Industrial Organization, Macroeconomics, and International Trade," Review of Economic Studies, 515-39.

Lambrecht, Anja, Katja Seim, and Bernd Skiera (2007), "Does Uncertainty Matter? Consumer Behavior under Three-Part Tariffs," Marketing Science, 26 (5), 698-710.

Lambrecht, Anja and Bernd Skiera (2006), "Paying Too Much and Being Happy About It:

Existence, Causes and Consequences of Tariff-Choice Biases," Journal of Marketing Research, 43 (May), 212-23.

Loewenstein, George F. (1987), "Anticipation and the Valuation of Delayed Consumption," The Economic Journal, 97 (September), 666-84.

Montgomery, Alan L., Shibo Li, Kannan Srinivasan, and John Liechty (2004), "Modeling Online Browsing and Path Analysis Using Clickstream Data," Marketing Science, 23 (4), 579-95. 
Nair, Harikesh (2008), "Intertemporal Price Discrimination with Forward-Looking Consumers: Application to the US Market for Console Video-Games," Quantitative Marketing \& Economics, 5 (3), 239 - 92.

Narayanan, Sridhar, Pradeep K. Chintagunta, and Eugenio J. Miravete (2007), "The Role of Self Selection and Usage Uncertainty in the Demand for Local Telephone Service," Quantitative Marketing and Economics, March (5), 1-34.

Olson, M. and M.J. Bailey (1981), "Positive Time Preference," Journal of Political Economy, 125.

Prelec, Drazen and George Loewenstein (1998), "The Red and the Black: Mental Accounting of Savings and Debt," Marketing Science, 17 (1), 4-28.

Read, Daniel, George Loewenstein, and Matthew Rabin (1999), "Choice Bracketing," Journal of Risk and Uncertainty, 19, 171-97.

Shampanier, Kristina, Nina Mazar, and Dan Ariely (2007), "Zero as a Special Price: The True Value of Free Products," Marketing Science, 26 (6), 745-57.

Thaler, Richard H. (1985), "Mental Accounting and Consumer Choice," Marketing Science, 4, 199-214.

Thaler, Richard H. (1999), "Mental Accounting Matters," Journal of Behavioral Decision Making, 12, 183-206.

Tversky, Amos and Daniel Kahneman (1981), "The Framing of Decisions and the Psychology of Choice," Science, 211 (4481), 453-58.

Viard, Brian (2007), "Do Switching Costs Make Markets More or Less Competitive?: The Case of 800-Number Portability," The Rand Journal of Economics, 38 (1), 146-63.

Wilson, Robert (1993), Nonlinear Pricing. New York: Oxford University Press.

Winer, Russel S. (2005), Pricing. Cambridge (Mass.): Marketing Science Institute.

Zauberman, Gal, B. Kyu Kim, Selin Malkoc, and James R. Bettman (2009), "Discounting Time and Time Discounting: Subjective Time Perception and Intertemporal Preferences," Journal of Marketing Research, 46 (4), 543-56. 
Figure 1: Evaluation of per period benefits and payments

(A)

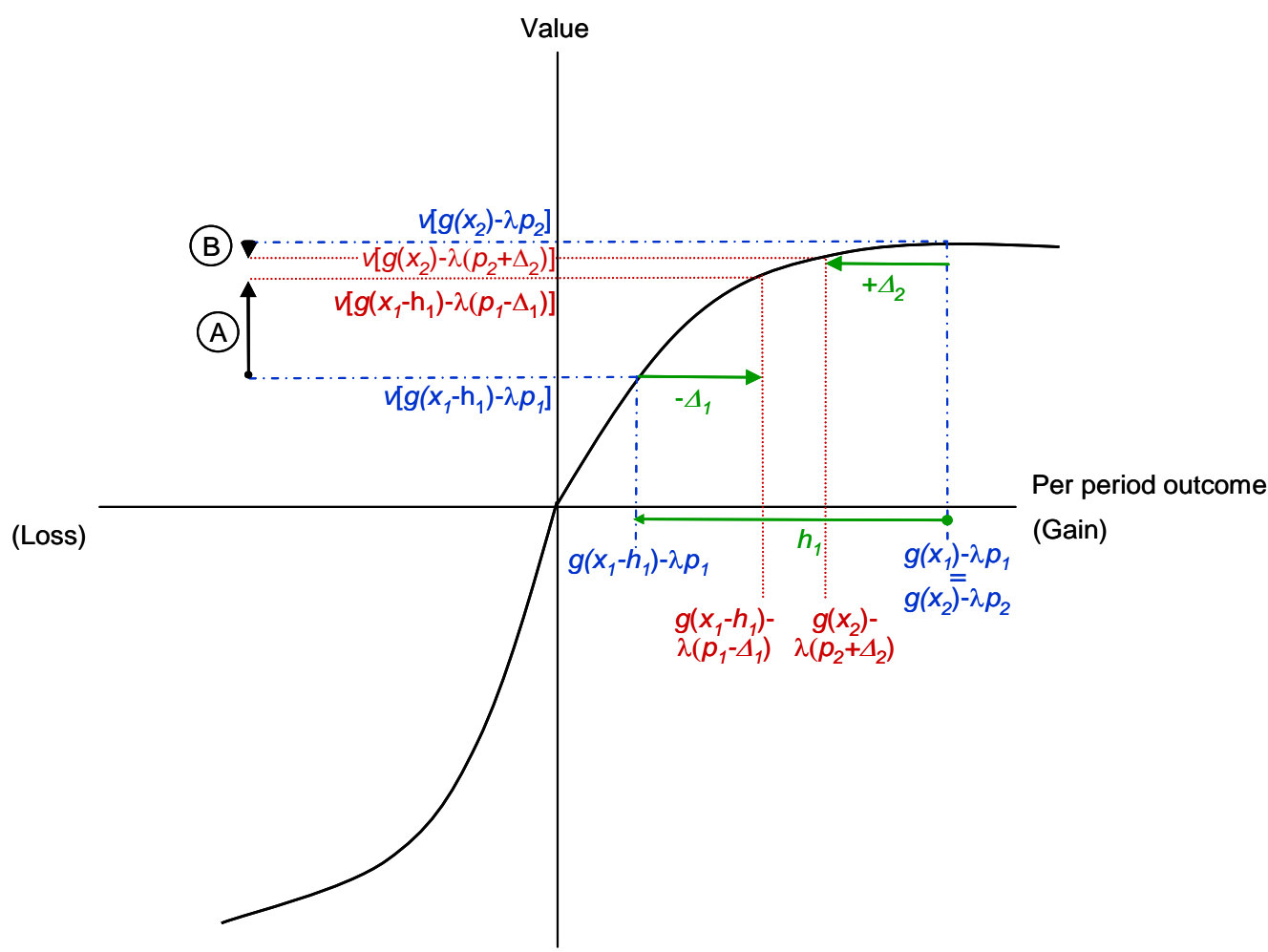

This figure assumes that in any time period $t$, marginal value from using a service decreases with the amount a customer consumes within that time period. $g\left(x_{1}-h_{1}\right)-\lambda p_{1}$ is the sum of service benefits, hassle costs and payments in period 1. $g\left(x_{2}\right)-\lambda p_{2}$ is the sum of service benefits and payments in period 2. A firm can decrease the amount it charges its customers in period 1 by $\Delta_{1}$ and increase this amount in period 2 by $d_{2}$, resulting in $g\left(x_{1}-h_{1}\right)-\lambda\left(p_{1}-\Delta_{1}\right)$ in period 1 and in $g\left(x_{2}\right)-\lambda\left(p_{2}+\Delta_{2}\right)$ in period 2 . As a result, the total value in period 1 increases by the amount (A) and the total value in period 2 decreases by the amount (B). As long as the marginal value decreases with increasing gains, as is typically assumed, the increase in period 1 value (A) is greater than the decrease in period 2 value (B).

Note that this figure does not allow comparison of outcomes of periods of different lengths. The $\mathrm{x}$-axis here denotes the per-period outcome for a fixed length of a period, e.g. a month or a year. An outcome of $g\left(x_{t}\right)-\lambda p_{t}$ per year (e.g., of 1200 hours yearly TV usage at a price of $\$ 480$ ) corresponds to a monthly outcome of $\frac{1}{12} g\left(x_{t}\right)-\lambda p_{t}$ (e.g., 100 hours monthly TV usage at a price of $\$ 40)$. The value of the per year outcome, $v_{\text {year }}\left(g\left(x_{t}\right)-\lambda p_{t}\right)$, translates into a per month outcome of $\frac{1}{12} v_{\text {year }}\left(g\left(x_{t}\right)-\lambda p_{t}\right)$. 
(B)

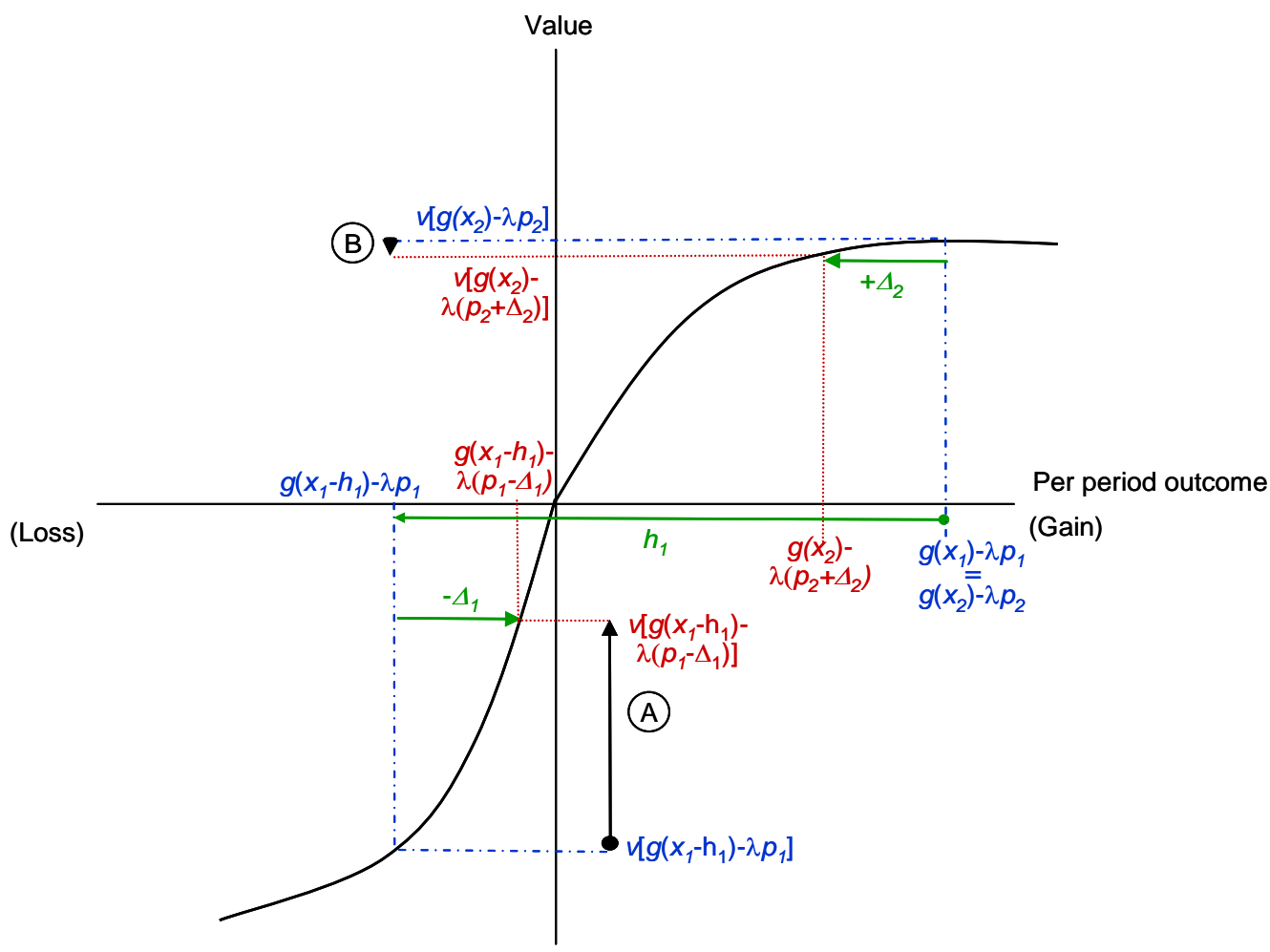

This figure assumes that a loss due to hassle costs weighs more heavily affects the value than positive outcomes in other periods. Hence, $g\left(x_{1}-h_{1}\right)-\lambda p_{1}$ is the sum of service benefits, hassle costs and payments in period 1. $g\left(x_{2}\right)-\lambda p_{2}$ is the sum of service benefits and payments in period 2. A firm can decrease the amount it charges its customers in period 1 by $d_{1}$ and increase this amount in period 2 by $d_{2}$, resulting in $g\left(x_{1}-h_{1}\right)-\lambda\left(p_{1}-d_{1}\right)$ in period 1 and in $g\left(x_{2}\right)-\lambda\left(p_{2}+d_{2}\right)$ in period 2 . As a result, the total value in period 1 increases by the amount (A) and the total value in period 2 decreases by the amount (B). 
Figure 2: Screenshots of different ads

\author{
Web Hosting Provider \\ 1st mo. £0, Then $£ 1.99 / \mathrm{mo}$. \\ Instant Setup, 3 mo. contracts \\ wWw co.uk \\ Web Host. No Hassle Setup \\ Just $£ 1.29 / \mathrm{mo}$. \\ Instant Setup, 3 mo. contracts \\ www co.uk \\ Web Hosting Provider \\ Just $£ 1.29 / \mathrm{mo}$. \\ Instant Setup, 3 mo. contracts \\ www. co.uk \\ Web Host. No Hassle Setup \\ 1st mo. £0, Then $£ 1.99 / \mathrm{mo}$. \\ Instant Setup, 3 mo. contracts \\ www ro.uk
}


Table 1: Keywords

\begin{tabular}{llrll}
\hline Keyword & Clicks & Impressions & Avg. Position & $\begin{array}{l}\text { Avg. Cost Per } \\
\text { Click }\end{array}$ \\
\hline web hosting & 149 & 35,923 & 4 & 6.16 \\
web host & 160 & 31,755 & 7 & 5.31 \\
UK web hosting & 20 & 3,282 & 10 & 5.21 \\
mysql hosting & 6 & 2,435 & 6 & 4.65 \\
web hosting UK & 16 & 1,462 & 10 & 5.29 \\
php web hosting & 8 & 1,075 & 6 & 4.77 \\
web host uk & 4 & 734 & 9 & 6.51 \\
hosting streamline & 8 & 584 & 2 & 5.52 \\
linux web hosting & 4 & 488 & 7 & 5.07 \\
quick web hosting & 3 & 398 & 5 & 5.11 \\
Monthly web hosting & 9 & 299 & 6 & - \\
web hosting provider & 0 & 286 & 9 & - \\
reliable web hosting & 0 & 192 & 8 & 5.76 \\
fantastico web & & & & - \\
hosting & 2 & 178 & 4 & - \\
reliable web host & 0 & 84 & 5 & 3 \\
safe web hosting & 0 & 65 & 3 & \\
\hline
\end{tabular}

Keywords describe the phrases which prompted the display of the ads. Generally, these keywords were part of a longer phrase that the consumer used as a "search term". The vast majority of search terms used by the 448 prospects were unique. The most popular search term, "web hosting", was used 6 times.

Table 2: Click through rates

\begin{tabular}{|c|c|c|c|}
\hline$\overline{A d}$ & Impressions & Clicks & Click Through Rate \\
\hline Web Host, No Hassle Setup & 17,922 & 71 & $0.40 \%$ \\
\hline $\begin{array}{l}\text { Ist mo. } £ 0 \text {, Then } £ 1.99 / \mathrm{mo} \text {. } \\
\text { Web Host, No Hassle Setup } \\
\text { Just } £ 1.29 / \text { mo. }\end{array}$ & 18,108 & 96 & $0.53 \%$ \\
\hline $\begin{array}{l}\text { Web Hosting Provider } \\
1 \text { st mo. } £ 0 \text {, Then } £ 1.99 / \mathrm{mo} \text {. }\end{array}$ & 21,884 & 115 & $0.53 \%$ \\
\hline $\begin{array}{l}\text { Web Hosting Provider } \\
\text { Just } £ 1.29 / \text { mo. }\end{array}$ & 21,325 & 97 & $0.45 \%$ \\
\hline
\end{tabular}


Table 3: Analysis of click-through rates

\begin{tabular}{|c|c|c|c|}
\hline & (1) & (2) & (3) \\
\hline Only Contractual & $0.0998^{* *}$ & $0.105^{* *}$ & $0.105^{* *}$ \\
\hline Discounting offered & $(0.0412)$ & $(0.0421)$ & $(0.0421)$ \\
\hline Only "No Hassle" & $0.0967^{* *}$ & $0.0888^{* *}$ & $0.0871^{* *}$ \\
\hline mentioned & $(0.0402)$ & $(0.0397)$ & $(0.0407)$ \\
\hline \multirow[t]{2}{*}{ Neither mentioned } & 0.0469 & 0.0459 & 0.0460 \\
\hline & $(0.0582)$ & $(0.0584)$ & $(0.0585)$ \\
\hline \multirow{2}{*}{\multicolumn{2}{|c|}{ Average daily ad position }} & -0.0228 & -0.0275 \\
\hline & & $(0.0183)$ & $(0.0175)$ \\
\hline \multirow[t]{2}{*}{ Constant } & $-2.655^{* * *}$ & $-2.503^{* * *}$ & $-2.506^{* * *}$ \\
\hline & $(0.0355)$ & $(0.120)$ & $(0.121)$ \\
\hline Day of week controls & No & No & Yes \\
\hline Observations & 79240 & 79240 & 79240 \\
\hline Log-Likelihood & -2400.5 & -2399.3 & -2397.7 \\
\hline
\end{tabular}

Probit estimates. Robust standard errors clustered at the daily level in parentheses

${ }^{*} p<0.10,{ }^{* *} p<0.05,{ }^{* * *} p<0.01$

Table 4: Subsequent browsing behavior, dependent variable: number of pages browsed

\begin{tabular}{|c|c|c|c|c|}
\hline & $\begin{array}{l}\text { (1) } \\
\text { All }\end{array}$ & $\begin{array}{c}(2) \\
\text { No-Interaction } \\
\end{array}$ & $\begin{array}{c}\text { (3) } \\
\text { Technical } \\
\end{array}$ & $\begin{array}{c}\text { (4) } \\
\text { Non-Technical } \\
\end{array}$ \\
\hline $\begin{array}{l}\text { Only "No Hassle" } \\
\text { mentioned }\end{array}$ & $\begin{array}{l}0.261^{* * *} \\
(0.0505)\end{array}$ & $\begin{array}{l}0.0767^{* *} \\
(0.0348)\end{array}$ & $\begin{array}{c}0.171 \\
(0.142)\end{array}$ & $\begin{array}{l}0.275^{* * *} \\
(0.0541)\end{array}$ \\
\hline $\begin{array}{l}\text { Only Contractual } \\
\text { Discounting offered }\end{array}$ & $\begin{array}{l}0.390^{* * *} \\
(0.0498)\end{array}$ & $\begin{array}{l}0.212^{* * *} \\
(0.0348)\end{array}$ & $\begin{array}{l}0.286^{*} \\
(0.154)\end{array}$ & $\begin{array}{l}0.399^{* * *} \\
(0.0528)\end{array}$ \\
\hline $\begin{array}{l}\text { "No Hassle" mentioned } \\
\text { and Contractual } \\
\text { Discounting offered }\end{array}$ & $\begin{array}{l}-0.357^{* * *} \\
(0.0704)\end{array}$ & & $\begin{array}{l}-0.0517 \\
(0.216)\end{array}$ & $\begin{array}{l}-0.393^{* * *} \\
(0.0746)\end{array}$ \\
\hline Constant & $\begin{array}{l}1.760^{* * *} \\
(0.0385) \\
\end{array}$ & $\begin{array}{l}1.862^{* * *} \\
(0.0311) \\
\end{array}$ & $\begin{array}{l}1.735^{* * *} \\
(0.108)\end{array}$ & $\begin{array}{l}1.763^{* * *} \\
(0.0412) \\
\end{array}$ \\
\hline $\begin{array}{l}\text { Observations } \\
\text { Log-Likelihood }\end{array}$ & $\begin{array}{c}448 \\
-2127.6 \\
\end{array}$ & $\begin{array}{c}448 \\
-2140.5\end{array}$ & $\begin{array}{c}52 \\
-138.5 \\
\end{array}$ & $\begin{array}{c}396 \\
-1987.0\end{array}$ \\
\hline
\end{tabular}


Table 5: Technical Searchers

Phrases in search terms used to identify technical searchers

Proportion of technical searchers

Proportion of technical searchers reaching webpage in no hassle condition

Proportion of technical searchers reaching webpage in contractual discounting condition

Average \# of webpages read by technical searchers

Average \# of webpages read by non-technical searchers
Php, mysql, jsp, servlet, cron job, atom, whm, flash, shell, sql, asp, ssh

$11.4 \%$

$11.5 \%$ vs $11.2 \%$ (p-value for difference is 0.9 )

$13.1 \%$ vs $9.3 \%$ ( $p$-value for difference is 0.19 )

7.37

7.5 
Table 6: Overview of lab experiments

\begin{tabular}{|l|l|l|l|l|}
\hline $\begin{array}{c}\text { Lab } \\
\text { experiment }\end{array}$ & $\begin{array}{l}\text { Time of hassle } \\
\text { in relationship }\end{array}$ & $\begin{array}{c}\text { Choice } \\
\text { between }\end{array}$ & \multicolumn{1}{|c|}{ Setting } & \multicolumn{1}{|c|}{ Shows that the effect holds when } \\
\hline 1 & Beginning & $\begin{array}{l}\text { Pricing } \\
\text { plans }\end{array}$ & $\begin{array}{l}\text { Fast Internet } \\
\text { Service }\end{array}$ & $\begin{array}{l}\text { - There is a clear end point to the contract } \\
\text { - Controlling for } \\
\text { - Consumer discount rates } \\
\text { - Perceptions of firm quality } \\
\text { - Perceptions of pricing plans }\end{array}$ \\
\hline 2 & During* & Discounts & Water Pipes & • Hassle occurs during a contract \\
\hline 3 & During & Discounts & Trains & $\begin{array}{l}\text { - The length of the bracket is varied to } \\
\text { either encompass the hassle or not }\end{array}$ \\
\hline 4 & During & Discounts & Health Club & $\begin{array}{l}\text { - The length of the bracket is varied to } \\
\text { increase the relative importance of } \\
\text { hassle costs relative to expected benefits }\end{array}$ \\
\hline 5 & End ${ }^{+}$ & $\begin{array}{l}\text { Pricing } \\
\text { plans }\end{array}$ & $\begin{array}{l}\text { Vacation } \\
\text { Rental } \\
\text { contract } \\
\text { - Consumers face larger monetary } \\
\text { expenditures than for most contractual } \\
\text { services }\end{array}$ \\
\hline
\end{tabular}

* Lab experiments A-2 and A-3 in the Online Appendix provide further evidence for hassle during the contract.

${ }^{+}$Lab experiment A-4 in the Online Appendix provides further evidence for hassle at the end of the contract. 
Table 7: Logit models of pricing plan choice in lab experiment 1

\begin{tabular}{|c|c|c|c|c|c|c|c|}
\hline Variable & (1) & (2) & $(3)^{+}$ & $(4)^{+}$ & $(5)^{+}$ & (6) & (7) \\
\hline Hassle & $0.932 * *$ & & $0.983 * *$ & & $0.921 * *$ & $0.954 * *$ & $1.028 * *$ \\
\hline condition & $(0.451)$ & & $(0.486)$ & & $(0.452)$ & $(0.471)$ & $(0.464)$ \\
\hline Level of hassle & & $\begin{array}{c}0.245^{* *} \\
(0.116)\end{array}$ & & $\begin{array}{c}0.391^{* *} \\
(0.153)\end{array}$ & & & \\
\hline $\begin{array}{l}\text { Good at } \\
\text { providing FiOS }\end{array}$ & & & $\begin{array}{c}0.075 \\
(0.226)\end{array}$ & $\begin{array}{c}0.318 \\
(0.264)\end{array}$ & & & \\
\hline Likely offered & & & & & & & \\
\hline - Constant plan & & & $\begin{array}{c}0.010 \\
(0.176)\end{array}$ & $\begin{array}{c}0.049 \\
(0.179)\end{array}$ & & & \\
\hline $\begin{array}{l}\text { - Contractual } \\
\text { discounting }\end{array}$ & & & $\begin{array}{c}0.070 \\
(0.136)\end{array}$ & $\begin{array}{c}0.074 \\
(0.137)\end{array}$ & & & \\
\hline Confusing & & & & & & & \\
\hline - Constant plan & & & $\begin{array}{c}0.176 \\
(0.229)\end{array}$ & $\begin{array}{c}0.210 \\
(0.231)\end{array}$ & & & \\
\hline $\begin{array}{l}\text { - Contractual } \\
\text { discounting }\end{array}$ & & & $\begin{array}{l}-0.011 \\
(0.141)\end{array}$ & $\begin{array}{c}0.014 \\
(0.145)\end{array}$ & & & \\
\hline
\end{tabular}

Discount rates

- Context-spec.

- 3 months

- 12 months

\begin{tabular}{lccccccc}
-12 months & & & & & & & 0.846 \\
Constant & $-0.446^{*}$ & $-0.914^{*}$ & $-2.233^{*}$ & $-4.936^{* *}$ & -0.618 & $-1.143^{* * *}$ & $-1.005^{* *}$ \\
& $(0.320)$ & $(0.496)$ & $(1.640)$ & $(2.159)$ & $(0.409)$ & $(0.442)$ & $(0.474)$ \\
\hline Log-Likelihood & -55.333 & -55.169 & -54.574 & -53.059 & -55.095 & -51.898 & -53.912 \\
\hline
\end{tabular}

${ }^{+}$Excluding the indicator for condition 2 or any other control variable does not lead to a significant effect of the remaining variables.

Dependent variable: Whether subject chose contractual discounting. Standard errors in parentheses, $\mathrm{N}=83$ ${ }^{*} p<0.10,{ }^{* *} p<0.05,{ }^{* * *} p<0.01$ 
Table 8: Logit models of discount choice in lab experiment 2

\begin{tabular}{|c|c|c|c|c|c|c|}
\hline Variable & (1) & (2) & $(3)^{+}$ & $(4)^{+}$ & $(5)^{+}$ & $(6)^{+}$ \\
\hline Hassle condition & $\begin{array}{l}1.167 * * \\
(0.499)\end{array}$ & & $\begin{array}{c}2.105^{* * *} \\
(0.780)\end{array}$ & & $\begin{array}{l}1.138 * * \\
(0.507)\end{array}$ & $\begin{array}{l}1.272 * * \\
(0.521)\end{array}$ \\
\hline Level of hassle & & $\begin{array}{l}0.237 * * \\
(0.029)\end{array}$ & & $\begin{array}{c}0.441^{* * *} \\
(0.166)\end{array}$ & & \\
\hline Company good & & & $\begin{array}{c}0.333 \\
(0.257)\end{array}$ & $\begin{array}{c}0.303 \\
(0.253)\end{array}$ & & \\
\hline Likely offered & & & & & & \\
\hline $\begin{array}{l}\text { - discount this } \\
\text { month }\end{array}$ & & & $\begin{array}{c}0.031 \\
(0.154)\end{array}$ & $\begin{array}{c}0.035 \\
(0.153)\end{array}$ & & \\
\hline - discount in three & & & -0.205 & -0.215 & & \\
\hline months from now & & & $(0.164)$ & $(0.166)$ & & \\
\hline Likely involve & & & -0.073 & -0.097 & & \\
\hline scenario & & & $(0.179)$ & $(0.181)$ & & \\
\hline Likely complete & & & 0.292 & 0.362 & & \\
\hline successfully & & & $(0.235)$ & $(0.244)$ & & \\
\hline $\begin{array}{l}\text { Discount rates (3 } \\
\text { months) }\end{array}$ & & & & & & \\
\hline $\begin{array}{l}\text { - Repair work } \\
\text { context }\end{array}$ & & & & & $\begin{array}{l}-0.303 \\
(0.201)\end{array}$ & \\
\hline - General & & & & & & $\begin{array}{c}-0.518^{* *} \\
(0.246)\end{array}$ \\
\hline Constant & $\begin{array}{c}-1.329 * * * \\
(0.375) \\
\end{array}$ & $\begin{array}{c}-1.734^{* * *} \\
(0.543)\end{array}$ & $\begin{array}{c}-3.817 * * \\
(1.638) \\
\end{array}$ & $\begin{array}{c}-4.734^{* *} \\
(1.908) \\
\end{array}$ & $\begin{array}{l}-0.811^{*} \\
(0.491) \\
\end{array}$ & $\begin{array}{l}-0.680 \\
(0.461) \\
\end{array}$ \\
\hline Log-Likelihood & -47.585 & -47.929 & -45.451 & -45.699 & -46.333 & -44.844 \\
\hline $\begin{array}{l}{ }^{+} \text {Excluding the inc } \\
\text { significant effect o } \\
\text { Dependent variabl } \\
\text { Standard errors in } \\
{ }^{*} p<0.10,{ }^{* *} p<0 \text {. }\end{array}$ & $\begin{array}{l}\text { ator for con } \\
\text { the remainin } \\
\text { Whether sub } \\
\text { irentheses, } \mathrm{N} \\
5,{ }^{* * *} p<0.0\end{array}$ & $\begin{array}{l}\text { tion } 2 \text {, the } \\
\text { variables. } \\
\text { ect chose di } \\
80\end{array}$ & sure of ha & $\begin{array}{l}\text { le or any of } \\
\text { of repair }\end{array}$ & other var & les does $n$ \\
\hline
\end{tabular}


Table 9: Logit models of discount choice in lab experiment 3

\begin{tabular}{|c|c|c|c|c|c|}
\hline Variable & (1) & (2) & (3) & (4) & (5) \\
\hline Hassle indicator & $\begin{array}{l}-0.388 \\
(0.495)\end{array}$ & $\begin{array}{l}-0.494 \\
(0.502)\end{array}$ & $\begin{array}{l}-0.397 \\
(0.520)\end{array}$ & $\begin{array}{l}-0.398 \\
(0.520)\end{array}$ & $\begin{array}{l}-0.059 \\
(0.086)\end{array}$ \\
\hline $\begin{array}{l}\text { Quarterly } \\
\text { indicator }\end{array}$ & $\begin{array}{l}-0.405 \\
(0.511)\end{array}$ & $\begin{array}{l}-0.387 \\
(0.514)\end{array}$ & $\begin{array}{l}-0.297 \\
(0.523)\end{array}$ & $\begin{array}{l}-0.297 \\
(0.523)\end{array}$ & $\begin{array}{l}-0.046 \\
(0.086)\end{array}$ \\
\hline $\begin{array}{l}\text { Hassle * quarterly } \\
\text { indicator }\end{array}$ & $\begin{array}{l}1.705^{* *} \\
(0.691)\end{array}$ & $\begin{array}{l}1.745^{* *} \\
(0.695)\end{array}$ & $\begin{array}{l}1.448^{* *} \\
(0.716)\end{array}$ & $\begin{array}{l}1.449 * * \\
(0.716)\end{array}$ & $\begin{array}{l}0.266 * * \\
(0.122)\end{array}$ \\
\hline Company good & & $\begin{array}{l}-0.183 \\
(0.135)\end{array}$ & $\begin{array}{l}-0.120 \\
(0.141)\end{array}$ & $\begin{array}{c}-0.121 \\
(0.143)\end{array}$ & $\begin{array}{l}-0.023 \\
(0.026)\end{array}$ \\
\hline Likely offered & & & & & \\
\hline $\begin{array}{l}\text { - discount next } \\
\text { month }\end{array}$ & & & $\begin{array}{c}-0.294 * * * \\
(0.102)\end{array}$ & $\begin{array}{c}-0.294 * * * \\
(0.102)\end{array}$ & $\begin{array}{c}-0.055 * * * \\
(0.018)\end{array}$ \\
\hline - discount & & & 0.187 & 0.188 & $0.034 *$ \\
\hline following month & & & $(0.122)$ & $(0.122)$ & $(0.021)$ \\
\hline $\begin{array}{l}\text { Discount rate } \\
\text { repair work } \\
\text { context (1 month) }\end{array}$ & & & & $\begin{array}{c}-0.002 \\
(0.031)\end{array}$ & $\begin{array}{c}0.000 \\
(0.005)\end{array}$ \\
\hline Constant & $\begin{array}{c}-1.153^{* * *} \\
(0.331)\end{array}$ & $\begin{array}{l}-0.206 \\
(0.766)\end{array}$ & $\begin{array}{l}-0.118 \\
(0.877)\end{array}$ & $\begin{array}{l}-0.096 \\
(0.931)\end{array}$ & $\begin{array}{c}0.448^{* * *} \\
(0.168)\end{array}$ \\
\hline Log-Likelihood & -106.870 & -105.960 & -101.454 & -101.451 & \\
\hline
\end{tabular}

${ }^{+}$We obtain similar results when including the context-independent instead of the context-specific discount rate. Models (1) to (4) are logit models.

Model (5) is a linear probability model to circumvent the problem of interpreting interaction terms (which are double-derivatives) within a logit framework. One issue of a logit probability model compared to a linear probability model is that the interpretation of interaction terms in logit and probit models is not straightforward (Ai and Norton 2003), as they are a cross-derivative of the expected value of the dependent variable. Therefore the sign of this marginal effect is not necessarily the same as the sign of the coefficient.

Dependent variable: Whether subject chose discount in month of repair work.

Standard errors in parentheses, $\mathrm{N}=197$

${ }^{*} p<0.10,{ }^{* *} p<0.05,{ }^{* * *} p<0.01$ 
Table 10: Logit models of pricing plan choice in lab experiment 4

\begin{tabular}{lcccc}
\hline Variable & $\mathbf{( 1 )}$ & $\mathbf{( 2 )}$ & $\mathbf{( 3 )}$ & $\mathbf{( 4 )}$ \\
\hline Hassle indicator & $1.443^{* * *}$ & $1.255^{* * *}$ & $1.217^{* * *}$ & $0.225^{* * *}$ \\
& $(0.319)$ & $(0.343)$ & $(0.345)$ & $(0.063)$ \\
Quarterly indicator & $0.625^{*}$ & $0.850^{* *}$ & $0.835^{* *}$ & $0.127^{* *}$ \\
& $(0.335)$ & $(0.359)$ & $(0.359)$ & $(0.063)$ \\
& & & & \\
Hassle * quarterly & $-1.249^{* * *}$ & $-1.350^{* * *}$ & $-1.294^{* * *}$ & $-0.237^{* * *}$ \\
indicator & $(0.438)$ & $(0.465)$ & $(0.467)$ & $(0.087)$ \\
& & $-0.263^{* * *}$ & $-0.265^{* * *}$ & $-0.050^{* * *}$ \\
Likely early & & $(0.0650)$ & $(0.065)$ & $(0.012)$ \\
discount & & & & \\
& & $0.362^{* * *}$ & $0.373^{* * *}$ & $0.070^{* * *}$ \\
Likely late discount & & $(0.075)$ & $(0.075)$ & $(0.013)$ \\
& & & 0.055 & 0.011 \\
Discount rate repair & & & $(0.051)$ & $(0.010)$ \\
work (3 months) & & & $-2.170^{* * *}$ & 0.098 \\
Constant & & & $(0.516)$ & $(0.094)$ \\
& $-1.425^{* * *}$ & $-2.018^{* * *}$ & & \\
\hline Log-Likelihood & $(0.256)$ & $(0.497)$ & & \\
\hline
\end{tabular}

${ }^{+}$We obtain similar results when including the context-independent instead of the context-specific discount rate. Models (1) to (3) are logit models. Model (4) is a linear probability model to circumvent the problem of interpreting interaction terms (which are double-derivatives) within a logit framework. One issue of a logit probability model compared to a linear probability model is that the interpretation of interaction terms in logit and probit models is not straightforward (Ai and Norton 2003), as they are a cross-derivative of the expected value of the dependent variable. Therefore the sign of this marginal effect is not necessarily the same as the sign of the coefficient.

Dependent variable: Whether subject chose discount in month of repair work.

Standard errors in parentheses, $\mathrm{N}=409$

${ }^{*} p<0.10,{ }^{* *} p<0.05,{ }^{* * *} p<0.01$

Table 11: Pricing plans in lab experiment 5

\begin{tabular}{lll}
\hline Condition & Constant pricing & Contractual Discounting \\
\hline $\begin{array}{l}\text { Same bill } \\
\text { Lower bill } \\
\text { contractual disc. }\end{array}$ & \$600 in each week from week 1 to week 3 & \$700 in week 1 and week 2, \$400 in week 3 \\
$\begin{array}{l}\text { Higher bill } \\
\text { contractual disc. }\end{array}$ & \$580 in each week from week 1 to week 3 & \$700 in week 1 and week 2, \$400 in week 3 \\
\hline
\end{tabular}


Table 12: Share of customers who choose contractual discounting in lab experiment 5

\begin{tabular}{llll}
\hline Condition & No hassle & Hassle & p-value \\
\hline (1) Same total bill & $19.6 \%$ & $50.0 \%$ & 0.000 \\
(2) Lower bill contractual disc. & $62.2 \%$ & $75.0 \%$ & 0.175 \\
(3) Higher bill contractual disc. & $7.5 \%$ & $20.8 \%$ & 0.051 \\
p-value (1) vs (2) & 0.000 & 0.009 & \\
p-value (2) vs (3) & 0.000 & 0.000 & \\
p-value (1) vs (3) & 0.067 & 0.002 & \\
\hline
\end{tabular}

Table 13: Models of pricing plan choice in lab experiment 5.

\begin{tabular}{|c|c|c|c|c|c|c|c|}
\hline Variable & (1) & (2) & (3) & (4) & (5) & $(6)^{+}$ & $(7)^{+}$ \\
\hline Hassle indicator & $\begin{array}{c}1.052 * * * \\
(0.276)\end{array}$ & & $\begin{array}{c}1.409 * * * \\
(0.436)\end{array}$ & $\begin{array}{c}1.572^{* * * *} \\
(0.465)\end{array}$ & $\begin{array}{c}1.611^{* * *} \\
(0.473)\end{array}$ & $\begin{array}{c}1.566 * * * \\
(0.477)\end{array}$ & $\begin{array}{c}0.316^{* * *} \\
(0.085)\end{array}$ \\
\hline Level of hassle & & $\begin{array}{c}0.136 * * \\
(0.068)\end{array}$ & & & & & \\
\hline $\begin{array}{l}\text { Lower bill } \\
\text { contractual disc. } \\
\text { Higher bill } \\
\text { contractual disc. }\end{array}$ & $\begin{array}{c}1.494^{* * *} \\
(0.310) \\
-1.225^{* * *} \\
(0.261)\end{array}$ & $\begin{array}{c}1.456 * * * \\
(0.302) \\
-1.208 * * * \\
(0.348)\end{array}$ & $\begin{array}{c}1.908^{* * *} \\
(0.456) \\
-1.097^{*} \\
(0.619)\end{array}$ & $\begin{array}{c}1.906^{* * *} \\
(0.460) \\
-1.161^{*} \\
(0.625)\end{array}$ & $\begin{array}{c}1.868 * * * \\
(0.468) \\
-1.297 * * \\
(0.636)\end{array}$ & $\begin{array}{c}1.864 * * * \\
(0.469) \\
-1.319 * * \\
(0.638)\end{array}$ & $\begin{array}{c}0.400 * * * \\
(0.084) \\
-0.148 * \\
(0.081)\end{array}$ \\
\hline Interactions & & & & & & & \\
\hline $\begin{array}{l}\text { - Hassle indicator } \\
\text { * lower bill } \\
\text { contractual disc. }\end{array}$ & & & $\begin{array}{l}-0.809 \\
(0.622)\end{array}$ & $\begin{array}{l}-0.819 \\
(0.629)\end{array}$ & $\begin{array}{c}-0.781 \\
(0.640)\end{array}$ & $\begin{array}{c}-0.729 \\
(0.644)\end{array}$ & $\begin{array}{c}-0.159 \\
(0.118)\end{array}$ \\
\hline $\begin{array}{l}\text { - Hassle indicator } \\
\text { * higher bill } \\
\text { contractual disc. }\end{array}$ & & & $\begin{array}{l}-0.243 \\
(0.758)\end{array}$ & $\begin{array}{l}-0.256 \\
(0.764)\end{array}$ & $\begin{array}{l}-0.133 \\
(0.779)\end{array}$ & $\begin{array}{l}-0.103 \\
(0.781)\end{array}$ & $\begin{array}{c}-0.143 \\
(0.115)\end{array}$ \\
\hline Enjoy vacation & & & & $\begin{array}{l}-0.042 \\
(0.107)\end{array}$ & $\begin{array}{l}-0.031 \\
(0.111)\end{array}$ & $\begin{array}{l}-0.033 \\
(0.111)\end{array}$ & $\begin{array}{l}-0.006 \\
(0.019)\end{array}$ \\
\hline $\begin{array}{l}\text { Return down- } \\
\text { payment }\end{array}$ & & & & $\begin{array}{c}0.192^{* *} \\
(0.091)\end{array}$ & $\begin{array}{c}0.203^{* *} \\
(0.093)\end{array}$ & $\begin{array}{c}0.197^{* *} \\
(0.094)\end{array}$ & $\begin{array}{c}0.033^{* *} \\
(0.016)\end{array}$ \\
\hline Time of payment & & & & & & & \\
\hline $\begin{array}{l}\text { - Weekly rate at } \\
\text { start of each week } \\
\text { - Weekly rate at } \\
\text { end of each week } \\
\text { - Full amount at } \\
\text { end of vacation }\end{array}$ & & & & & $\begin{array}{c}-0.426 \\
(0.324) \\
0.520 \\
(0.340) \\
1.071^{*} \\
(0.594)\end{array}$ & $\begin{array}{c}-0.434 \\
(0.325) \\
0.534 \\
(0.400) \\
1.109^{*} \\
(0.598)\end{array}$ & $\begin{array}{c}-0.068 \\
(0.055) \\
0.093 \\
(0.069) \\
0.185^{*} \\
(0.100)\end{array}$ \\
\hline $\begin{array}{l}\text { Discount rates } \\
-3 \text { months }\end{array}$ & & & & & & $\begin{array}{l}-0.097 \\
(0.138)\end{array}$ & $\begin{array}{c}-0.012 \\
(0.022)\end{array}$ \\
\hline Constant & $\begin{array}{c}-1.202^{* * *} \\
(0.261)\end{array}$ & $\begin{array}{c}-1.217^{* * *} \\
(0.353)\end{array}$ & $\begin{array}{c}-1.409 * * * \\
(0.336) \\
\end{array}$ & $\begin{array}{c}-2.186^{* * *} \\
(0.743)\end{array}$ & $\begin{array}{c}-2.319 * * * \\
(0.797)\end{array}$ & $\begin{array}{c}-2.160 * * * \\
(0.829) \\
\end{array}$ & $\begin{array}{c}0.081 \\
(0.137) \\
\end{array}$ \\
\hline Log-Likelihood & -164.981 & -170.594 & -164.109 & -161.712 & -156.794 & -156.545 & \\
\hline
\end{tabular}

Models (1) to (6) are logit models.

Model (7) is a linear probability model to circumvent the problem of interpreting interaction terms (which are double-derivatives) within a logit framework. One issue of a logit probability model compared to a linear probability model is that the interpretation of interaction terms in logit and probit models is not straightforward (Ai and Norton 2003), as they are a cross-derivative of the expected value of the dependent variable. Therefore the sign of this marginal effect is not necessarily the same as the sign of the coefficient.

Dependent variable: Whether subject chose contractual discounting.

Standard errors in parentheses, $\mathrm{N}=311$

${ }^{+}$Similar results for 12-month instead of 3-month discount rate.

${ }^{*} p<0.10,{ }^{* *} p<0.05,{ }^{* * *} p<0.01$ 


\section{Online Appendix Paying With Money or With Effort: Pricing When Customers Anticipate Hassle}

This Online Appendix provides further detail on the field experiment and on the lab experiments.

First, it gives an overview of the web hosting industry and lays out post-tests of the field

experiment. Second, it reports four additional lab experiments. Third, it discusses in detail the discount rates that were measured in our lab experiments and the evidence for hyperbolic discounting. 


\section{FIELD EXPERIMENT}

\section{Search advertising and field experiments}

Our field experiment uses the context of search advertising. A growing body of literature studies the empirical properties and mechanisms that underlie search advertising (see Rutz and Bucklin 2008; Goldfarb and Tucker 2007). However, to our knowledge, researchers have so far not used search advertising as a platform to test customer preferences more generally.

Using search advertising for our experimental manipulation offers four advantages. First, it is easy to adjust advertising messages to downplay hassle costs. Second, it is easy to randomize who sees the ad. Third, the ad targets an audience that has not yet chosen the service, which matters because here hassle costs largely take the form of setup costs. Last, the effectiveness of a search advertising campaign is immediately measurable.

\section{Industry Setting}

In 2007, there were 26,434 hosting companies in the US and 2,802 hosting companies in the UK. The large number of companies reflects the large number of websites that are being continually set up. For example, in the UK, it was estimated in 2005 that 110,000 websites with a "co.uk" suffix were set up every month. ${ }^{1}$ The typical market share of any one company is small. The 20th largest web hosting company, "hosthostuk.co.uk" (which is larger than the hosting company that we study), hosts only 18,567 domains, with a $0.5 \%$ market share. ${ }^{2}$

There are three major characteristics of the service offered. First, the customer chooses the amount of storage space needed for the website. Second, the customer chooses the amount of bandwidth which is governed by the amount of expected traffic. Third, firms offer different

\footnotetext{
1 "UK internet industry continues to grow", August 17 2005, http://www.webuser.co.uk

2 Information from http://www.webhosting.info
} 
levels of technical support and software provision. For example, the firm we study provided 24hour e-mail technical support, and a Linux/PHP backbone for constructing and hosting websites. They also provided a clustered server system that protected against extended periods of downtime. Typically, when customers buy a service plan, they choose a "package” of maximum storage space, bandwidth and a service level.

Differences in hassle costs arise because of the different tools webhosting providers offer. With some web-hosting providers, e.g. Google Sites, hassle costs are low since they offer templates for setting up a website. Other providers (especially those based around a combined UNIX, Perl and mySQL operating system) require their customers to set up a website from scratch relying on forums and user-based content for guidance.

In general, identifying the effect of hassle costs on customer choices is hard. Without randomization over claims about hassle costs, such as in our field experiment, such costs may be confounded with many other observable or unobservable product attributes such as quality and reputation. It is usually hard for firms to vary the degree of perceived hassle costs, as this would involve multiple separate "product designs" which would be both costly and difficult to implement without antagonizing customers. Using field tests to influence expectations through advertising has traditionally only been possible using “direct-response” advertising, but direct response is rarely used to sell technology services.

The ads manipulated two types of information: The hassle required to set up a website (e.g., to set up FTP connections or user permissions), and the availability of contractual discounting. If people prefer the pattern of monetary costs to reflect their pattern of hassle costs, then firms' use of contractual discounting should be more attractive to customers when firms do 
not explicitly communicate hassle costs than when they inform customers that there would be no hassle in setting up the website.

The average cost to the firm each time a customer clicked on one of these messages was between $\$ 4.52$ and $\$ 6.91$ per click.

\section{Testing the Advertising Message}

We conducted three post-tests of the advertising messages used in the field experiment with subjects recruited on the Mechanical Turk and allocated randomly to one of the four ads that were used in the field experiment and displayed in Figure 2 in the paper.

First, we confirmed that "No Hassle” ads successfully induced a lower perceived level of hassle. We found that 318 subjects who each saw one of the four ads thought that setting up the website would be less effort, would be easier and would take less time when the company advertises “No Hassle” (effort: 2.503 vs. 3.717, easy: 2.371 vs. 3.686, time: 2.472 vs. 3.761, all $\mathrm{p}=0.000)$.

Second, to find out whether customers take the contract terms seriously, we showed the ads to 200 subjects and asked whether they think the advertising message " 3 mo. contracts" means that they are required to finish the contract and cannot break it early. 95\% said that they assumed they would not be able to break the contract. There was no significant difference between people in different "hassle" conditions for the 5\% who thought they could break the contract. There was no significant difference ( $p$-value $=0.78$ ) between people who had set up a website (5\%) compared to those who had not set up a website (5\%).

Third, we asked the same 200 subjects how they perceive the message "instant setup.” 71\% perceived the message as referring to the intended feature that the URL would be automatically hosted without need for further administrative approvals. 15\% thought that it 
referred to software templates and tools that made it easier to create websites. The remaining $14 \%$ were unsure. There was no significant difference in perceptions between subjects that saw the "no hassle" ad and subjects that saw an ad that did not mention "no hassle". (74\% and 67\% thought it referred to automatic hosting, $p$-value $0.52 .13 \%$ and $16 \%$ thought it referred to software tools, $p$-value $=0.32$.)

\section{Testing for Differences in Discount Rates}

In a field experiment, it is difficult to measure customers' discount rates. However, to provide some evidence that customers' discount rates are not driving the effect we observe, we test whether subjects who have experience in searching for or setting up a webhosting provider have different discount rates than other subjects. If discount rates drive the effect we observe, subjects with more experience who, as our stratification by "technical” and "non-technical” users suggests, are less sensitive to the "no hassle" prime, should have lower discount rates.

Building on prior research (Zauberman et al. 2009), we tell 128 subjects from a university subject pool to imagine they have received a $\$ 75$ gift certificate and then ask them to indicate how much they would need to be paid to delay using the gift certificate for three months. We repeat the same question with a 12-month delay. We also ask them about their experience in searching for a web hosting provider and in setting up a website. We find that the 35 subjects who have searched for a web hosting provider have similar discount rates as the 93 subjects who have never searched for a web hosting provider ( 3 months: 0.694 vs. $0.717, \mathrm{p}=0.849$; 12 months: 0.365 vs. $0.397, \mathrm{p}=0.506$ ). Similarly, we find that discount rates of the 18 subjects who have set up a website are not significantly different from discount rates of the 110 subjects who have never set up a website ( 3 months: 0.697 vs. $0.719, p=0.887 ; 12$ months: 0.365 vs. 0.429 , $\mathrm{p}=0.300)$. 
We conduct a similar robustness check using 76 subjects on the Mechanical Turk. Using the same question as above, we measure 3-month and 6-month discount rates, as well as subjects' experience in searching for a web hosting provider and in setting up a website. We find that the 32 subjects who have searched for a web hosting provider have similar discount rates as the 44 subjects who have never searched for a web hosting provider (3 months: 1.021 vs. 1.369, $\mathrm{p}=0.233$; 6 months: 0.770 vs. $0.970, \mathrm{p}=0.552$ ). Similarly, we find that discount rates of the 20 subjects who have set up a website are not significantly different from discount rates of the 56 subjects who have never set up a website ( 3 months: 1.163 vs. $1.243, p=0.807 ; 6$ months: 0.838 vs. $0.903, \mathrm{p}=0.748)$.

\section{LAB EXPERIMENTS}

We first report four additional lab experiments that are situated in the context of maintaining an existing service and one additional lab experiment where hassle costs arise from disposal. We then present in detail the results on discount rates that we measure across our lab experiments. We also discuss evidence for hyperbolic discounting.

\section{Lab Experiment A-1: Hassle at the Beginning, Choice Setting}

Design and procedure. We study how hassle costs affect customers' choices of constant monthly pricing versus contractual discounting, in a setting of a web hosting provider similar to our field experiment.

Subjects are directed to the home page of a web hosting provider set up for the purpose of the study. The home page offers information on web hosting services and pricing schemes. There is a "Hosting Services” webpage with more detailed information and a webpage that allows 
customers to check domain availability. This website offers web hosting with 1000MB storage space and 1GB file transfer. Customers choose between two pricing plans. One plan charges \$2.49 every month for three months (constant monthly pricing). The other plan offers contractual discounting, charging $\$ 0.00$ in the first month and \$3.89 in months 2 and 3. The contractual discounting plan is $\$ 0.31$, or $4.1 \%$ more expensive than the constant-pricing plan. Subjects are told that no setup fee will be charged and that they can switch providers after the third month.

Subjects are randomly assigned to one of two experimental conditions. Both conditions feature constant pricing and contractual discounting and general information about the service. Condition 1 serves as our baseline to calibrate the preference for contractual discounting versus constant pricing. Here, no information on the level of hassle is provided. Condition 2 communicates a lower level of hassle: the home page and the hosting services web page prominently provide information on a "Fast and Easy No-Worries Setup" (Figure 1). The site also features a new "No-Worries Setup" web page (Figure 2). This web page details the "Fast and Easy No-Worries Setup”, provides a “Step-by-Step Guide” on how to successfully set up a website and gives testimonials from (imaginary) customers. We expect that significantly fewer subjects will choose contractual discounting in Condition 2.

Subjects are a total of 120 graduate and undergraduate students from two major US universities as well as subjects recruited through an e-lab program. All participants have a chance to win a $\$ 30$ gift certificate for Amazon.com. Subjects are randomly assigned to conditions (64 responses to Condition 1 and 56 to Condition 2).

Results. In the baseline Condition 1, 35.9\% of subjects choose the more expensive contractual discounting plan. In Condition 2, where the website talks about low setup costs, significantly fewer subjects, $17.9 \%$, choose contractual discounting $(\mathrm{p}=0.045)$. This extends the 
results of our field experiment to actual choice. We conclude that the level of hassle costs that the firm communicates affects customers' choice of pricing plans.

Figure 1: Information on "no-worries setup” on homepage and hosting services page

\section{WHAT WE OFFER}

FAST AND EASY NO-WORRIES SETUP

Setting up your web site with Hostingcertainty is extremely fast and easy.

We provide you with all the advice needed to set up your web site. With Hostingcertainty you can be sure that your web site is up and running on day one. Check out our NO-WORRIES SETUP

Figure 2: No-worries setup webpage in lab experiment 1

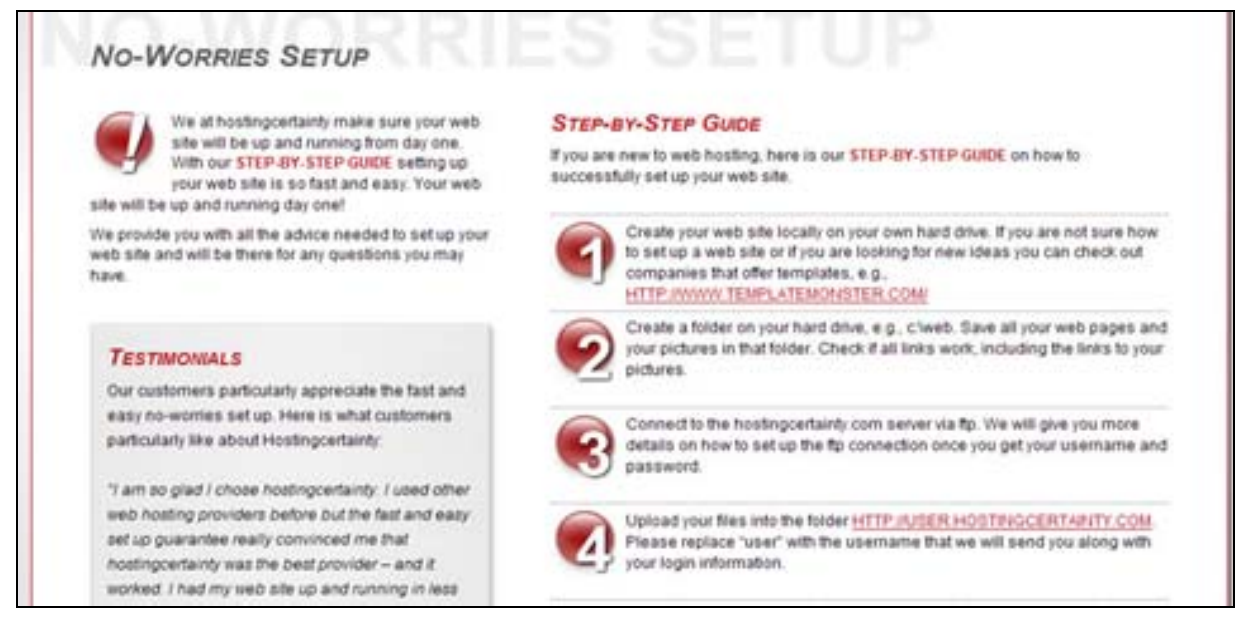

\section{Lab experiment A-2: Hassle During a Contract (photo editing software)}

Design and procedure. We focus on how hassle costs in maintaining a service during a contract affect preferences. Here, we do not consider the choice between constant pricing and contractual discounting, as we do in lab experiments 3 and 4 of the main paper. Instead, we offer two contracts with discounts at different points in time. This allows us to rule out that differences 
in the complexity of both pricing plans drive our results. We expect customers with hassle costs to be likelier to prefer a discount in the period of hassle than customers with no hassle costs.

We instruct subjects to imagine they are a keen photographer buying an online photoediting and storage service. They know that in six months the company will move the location of the servers that host the service. In Condition 1, subjects are told "Luckily this will be effortless as all your default settings will be imported" and in Condition 2 "Unfortunately, this will be very inconvenient for you as you will have to spend half a day reorganizing all your photos as this relocation will lead the company to lose its customers' personalized settings.” In both conditions, subjects then choose between " $\$ 10$ in this month and \$20 in all other month" and "\$10 in month six (when the company moves its servers) and \$20 in all other months.”

Similarly to the previous lab experiment, we measure how much hassle subjects think the change in location of the servers will involve for them. We ask how good they think the company is overall (1: "very bad”, 7: "very good”) and how likely they think it is that the service will be working after the change in server location [Condition 2: and after they reorganized the photos] (1: "very unlikely”, 7: “very likely”). To test whether subjects find the scenario realistic, we ask how likely they think such a company is to change the location of their servers.

Since the discount that matches the hassle is applied in a later period, we do not expect discount rates to affect choice. Still, we measure both context-specific and context-independent discount rates. First, we tell subjects to imagine that the company charged $\$ 20$ per month but sent a discount voucher of $\$ 10$ valid for this month. We ask them how much they would need to be paid to consider delaying the use of the discount by three months and by six months. Second, we measure three- and six-month context-independent discount rates, as in lab experiment 2. 
If customers wish their monetary costs to reflect the pattern of their benefits, the share of customers that chooses the pricing plan that charges $\$ 10$ in the month of relocation of the servers should be greater in Condition 2 when customers have greater hassle costs. This would confirm that customers engage in period-level bracketing. Subjects would knowingly forego an early discount in favor of a late discount, and choose a discount with a lower net present value.

69 subjects were recruited through the Mechanical Turk and randomly assigned to one of the conditions (36 responses for Condition 1, 33 responses for Condition 2).

Results. The experiment successfully manipulated the perceived level of hassle across conditions (2.583 vs. 6.091, $\mathrm{p}=0.000$ ). Subjects, as expected, are significantly more likely to choose the discount in the replacement month if the replacement involves hassle (19.4\% vs. 66.7\%, $\mathrm{p}=0.000$; column (1), Table A- 1). We find that it is indeed the perceived level of hassle that affects choice (column (2)). None of the control variables are significantly different between conditions. Their inclusion in the logit model does not mitigate the effect of our main variables of interest, the condition and the level of hassle, on choice (columns (3) and (4)). We further find that subjects do not rate the offered plans as significantly more complicated than a plan that charges \$20 in each month (\$10 in month 1: 3.057, \$10 in month 6: 3.928, \$20 in each month: 4.058). As expected, discount rates do not affect the choice of pricing plan (columns (5) and (6), similar results for 12-month discount rates).

The results confirm that customers wish the pattern of their monetary costs to reflect the pattern of their benefits on a payment-period level when hassle costs stem from product maintenance during a contract. The results also rule out as confounds a preference for early discounts, the complexity of the pricing plans or discounting. 
Table A- 1: Logit models of discount choice in lab experiment A-2

\begin{tabular}{|c|c|c|c|c|c|c|}
\hline Variable & (1) & (2) & (3) ${ }^{+}$ & $(4)^{+}$ & $(5)^{+}$ & $(6)^{+}$ \\
\hline $\begin{array}{l}\text { Condition } 2 \\
\text { (hassle) }\end{array}$ & $\begin{array}{c}2.114 * * * \\
(0.560)\end{array}$ & & $\begin{array}{c}2.330 * * * \\
(0.639)\end{array}$ & & $\begin{array}{c}2.103^{* * *} \\
(0.561)\end{array}$ & $\begin{array}{c}2.110^{* * *} \\
(0.561)\end{array}$ \\
\hline Level of hassle & & $\begin{array}{c}0.451^{* * * *} \\
(0.141)\end{array}$ & & $\begin{array}{c}0.455^{* * *} \\
(0.155)\end{array}$ & & \\
\hline Company good & & & $\begin{array}{c}0.465 \\
(0.340)\end{array}$ & $\begin{array}{c}0.426 \\
(0.324)\end{array}$ & & \\
\hline Service will work & & & $\begin{array}{c}-0.670^{* *} \\
(0.889)\end{array}$ & $\begin{array}{l}-0.470 \\
(0.317)\end{array}$ & & \\
\hline Likely relocate & & & $\begin{array}{c}0.146 \\
(0.185)\end{array}$ & $\begin{array}{c}0.128 \\
(0.179)\end{array}$ & & \\
\hline Plans complicated & & & & & & \\
\hline - $\$ 10$ this month & & & $\begin{array}{c}0.045 \\
(0.155)\end{array}$ & $\begin{array}{c}0.082 \\
(0.144)\end{array}$ & & \\
\hline $\begin{array}{l}\text { - } \$ 10 \text { in six } \\
\text { months from now }\end{array}$ & & & $\begin{array}{l}-0.177 \\
(0.189)\end{array}$ & $\begin{array}{l}-0.180 \\
(0.179)\end{array}$ & & \\
\hline $\begin{array}{l}\text { Discount rates (6 } \\
\text { months) }\end{array}$ & & & & & & \\
\hline $\begin{array}{l}\text { - Photo online } \\
\text { service context }\end{array}$ & & & & & $\begin{array}{c}0.089 \\
(0.227)\end{array}$ & \\
\hline - General & & & & & & $\begin{array}{c}0.063 \\
(0.403)\end{array}$ \\
\hline Constant & $\begin{array}{c}-1.421^{* * *} \\
(0.421)\end{array}$ & $\begin{array}{c}-2.319 * * * \\
(0.7042) \\
\end{array}$ & $\begin{array}{c}-0.241 \\
(1.695)\end{array}$ & $\begin{array}{c}-1.983 \\
(1.846)\end{array}$ & $\begin{array}{c}-1.583 * * * \\
(0.587)\end{array}$ & $\begin{array}{c}-1.468 * * * \\
(0.520)\end{array}$ \\
\hline Log-Likelihood & -38.739 & -40.905 & -35.387 & -38.466 & -38.657 & -38.727 \\
\hline
\end{tabular}

\section{Lab Experiment A-3: Hassle During a Contract (Cable TV)}

Design and procedure. We focus on how hassle costs in maintaining a service during a contract affect preferences. Here, we do not consider the choice between constant pricing and contractual discounting but instead offer customers to choose between two discounts that only differ in their timing. This also allows us to rule out that differences in the complexity of both pricing plans drive our results. We analyze whether customers would prefer a discount in the period of hassle to an earlier discount. We expect that greater hassle during a contract leads to a greater preference to receive a discount in that period. 
Subjects are told to imagine that they have been a loyal customer of their cable TV company for several years and are paying \$38 every month for cable TV. They are an intense user of their digital video recorder (DVR) which is set to record several shows a day. The cable TV company has to do a routine replacement of their set-top box three months from now. In Condition 1, subjects are told "The cable company will deliver and install the box at a time that is convenient for you. Your DVR programming and recorded shows will not be affected.” In Condition 2, subjects are told "The new box will not have your DVR programming selections so installation will be lengthy. The day you receive the box you will need to reprogram your DVR from scratch. You will also need to transfer your recorded programs to the new DVR. It will take several hours to study the instructions, reprogram the shows to be recorded, and transfer the shows already recorded.” All subjects are then told the company offers them a one-off discount of \$30. They are told to imagine that they need the TV and DVR this month as much as in three months from now. They then choose between applying this discount this month or three months from now when the replacement of the set-top box is scheduled.

Subjects then answer questions regarding the scenario. We measure how much hassle subjects think the replacement of the set-top box will involve for them and how good they think the company is overall (1: “very bad”, 7: “very good”). Subjects are also asked whether they think it is likely that the company offers each of the discounts, how likely they think a cable company is to do a routine replacement of the set-top box, and how likely they think it is that the TV and DVR will be working at the end of the day that the cable company delivered and installed [Condition 2: and they installed] the set-top box. We measure context-specific and context-independent discount rates. First, we tell subjects to imagine that instead of offering a choice between discounts, the cable company sent a $\$ 30$ discount voucher valid this month. We 
ask them how much they would need to be paid to consider delaying the use of the discount by 3 months and by 12 months. Second, we measure 3- and 12-month context-independent discount rates, as we did in lab experiment 1.

If customers indeed wish their monetary costs to reflect the pattern of their benefits, the share of customers that chooses the discount in the month of replacement should be greater when customers have greater hassle costs, i.e. in Condition 2. This would provide additional evidence that period-level bracketing drives customer preferences. It would also illustrate that firms can use the timing of discounts to respond to hassle costs that occur during a contract.

116 subjects were recruited through the Mechanical Turk and randomly assigned to one of the conditions (53 responses for Condition 1, 63 responses for Condition 2).

Results. We successfully manipulated the perceived hassle across conditions (2.943 vs. 6.016, $\mathrm{p}=0.000$ ). Our results confirm that subjects are significantly more likely to choose the discount in the replacement month if the replacement involves greater hassle (18.9\% vs. 39.7\%, $\mathrm{p}=0.015$ and columns (1), Table A- 2). We find that it is indeed the perceived level of hassle that affects choice (column (2)). We check whether perceptions of the company affect the results. Subjects in Condition 1 rate the company as slightly better than subjects in Condition 2 (4.887 vs. 4.063, $\mathrm{p}=0.001)$. Also, subjects in Condition 1 think it is more likely that the TV and DVR will work at the end of the day of installation than subjects in Condition 2 (5.396 vs. 4.016, $\mathrm{p}=0.000$ ). Subjects do not find it unlikely that the cable company does a routine replacement of the set-top box (4.340 vs. 4.492, p=0.617). In neither of the conditions they find it more likely that the company would give an early or late discount. None of the control variables affect the results (columns (3) and (4)). Similarly, discount rates do not differ across conditions or affect choice of discounts (columns (5) and (6), similar results for 12-month discount rates). 
The results reinforce that customers are willing to forego earlier discounts to match a lower payment with greater hassle, confirming that customers engage in period-level bracketing. They also show that firms can use discounts to respond to hassle they impose on consumers through service maintenance in the middle of a contract.

Table A- 2: Logit models of discount choice in lab experiment A-3

\begin{tabular}{lcccccc}
\hline Variable & $\mathbf{( 1 )}$ & $\mathbf{( 2 )}$ & $\mathbf{( 3 )}^{+}$ & $\mathbf{( 4 )}^{+}$ & $\mathbf{( 5 )}^{+}$ & $\mathbf{( 6 )}^{+}$ \\
\hline Condition 2 & $1.040^{* *}$ & & $1.082^{* *}$ & & $1.039^{* *}$ & $1.030^{* *}$ \\
(hassle) & $(0.435)$ & & $(0.486)$ & & $(0.439)$ & $(0.437)$ \\
Level of hassle & & $0.277^{* *}$ & & $0.310^{* *}$ & & \\
& & $(0.115)$ & & $(0.136)$ & \\
Company good & & & -0.228 & -0.227 & \\
& & & $(0.166)$ & $(0.168)$ &
\end{tabular}

Likely offered

- discount this month

- discount in three

(0.121) (0.120)

months from now

$0.007 \quad-0.006$

Likely routine

(0.129) (0.129)

replacement

$0.086 \quad 0.053$

Likely work at

$(0.143)$

$(0.145)$

end of day

0.152

0.181

(0.141) (0.145)

Discount rates (3

months)

- Cable company

context

- General

\begin{tabular}{lcccccc} 
& & & & \\
Constant & $-1.459 * * *$ & $-2.176 * * *$ & -1.602 & $-2.484^{*}$ & $-1.456 * * *$ & $-1.268 * * *$ \\
& $(0.351)$ & $(0.614)$ & $(1.245)$ & $(1.434)$ & $(0.429)$ & $(0.423)$ \\
\hline Log-Likelihood & -67.985 & -67.861 & -66.528 & -66.302 & -67.985 & -67.677 \\
\hline${ }^{+}$Excluding the indicator for condition 2, the measure of hassle or any of the other variables does not lead to a \\
significant effect of the remaining variables. \\
Dependent variable: Whether subject chose discount in month of replacement. \\
Standard errors in parentheses, $\mathrm{N}=116$ \\
${ }^{*} p<0.10,{ }^{* *} p<0.05,{ }^{* * *} p<0.01$
\end{tabular}

\section{Lab Experiment A-4: Hassle at the End of a Contract (Telephone Service)}

Design and procedure. We aim to show that customers want to match lower payments with hassle costs even if hassle costs occur at the end of the contract. This is a strong test of our 
theory, since subjects would choose the option with a lower net present value. The study also suggests that firms can use discounts at the end of a contract to respond to hassle costs.

Subjects are asked to imagine working as a freelancer for six months in Chile, after which they will return to the US. The telephone company is about to connect the line. In Condition 1, subjects are told, "Connecting the service is easy. You know from a previous experience in Chile that cancelling the service is also quick and a matter of only a short phone call.” In Condition 2, they are told "Connecting the service is easy. But you know from a previous experience in Chile that cancelling is a lot of hassle: you speak only a little Spanish and people at the local Chilean telephone company rarely speak good English. It's never clear which department is responsible for line cancellation and you are usually passed through different departments. As a result, you typically spend several hours on the phone trying to cancel your line.” All subjects are told that as the company is about to connect the service, it offers the choice between two $\$ 30$ discounts: a “Thank you for giving us your business"-discount in the first month and a "Thank you for being our customer"-discount in the last month of the contract. Subjects are asked to think about the process of cancellation and choose one discount. Then, we ask for the perceived level of hassle of line cancellation. We ask whether subjects agree that the company will provide high-quality phone service (1: “strongly disagree”, 7: “strongly agree”) and whether they think it likely that the company offers the discounts. As before, we measure context-independent discount rates. If customers indeed engage in period-level bracketing and wish their monetary costs to reflect the pattern of their hassle costs, the share of customers that chooses the discount in the last month should be greater in Condition 2, when customers have greater hassle costs. Subjects would choose a plan with a lower net present value and forego the option of trying to extract the 
discount and then terminating their contract early, or of strategically aiming to secure further discounts from the company after having benefited from the offer. ${ }^{3}$

152 subjects were recruited through the Mechanical Turk and randomly assigned to a condition (79 responses for Condition 1, 73 responses for Condition 2).

Results. Perceived hassle is lower in Condition 1 than in Condition 2 (2.696 vs. 5.616, $\mathrm{p}=0.000$ ). As expected, subjects in Condition 2 are more likely to choose the discount in the last month (11.4\% vs. 30.1\%, $\mathrm{p}=0.004$; columns (1) and (2), Table A-3).

We test whether the control variables affect choice. Customers believe the company is more likely to provide high-quality phone service in Condition 1 than in Condition 2 (4.608 vs. 3.932, $\mathrm{p}=0.000$ ) but this does not significantly affect plan choice. Overall, subjects think that the company is slightly more likely to offer the discount in the first month than in the last month (4.979 vs. 4.004, $\mathrm{p}=0.000$ ) but this does not affect plan choice (column (3)). None of the discount rates are significantly different across conditions and as expected they do not significantly affect plan choice (columns (4) and (5)).

The results provide further evidence for the mechanism underlying our results: The strong preference for a discount in the last month only when hassle occurs in that month is evidence that customers prefer their monetary costs to reflect the pattern of their hassle costs over time. It also rules out that customers' preference is driven by a lower net present value of the stream of payments. As a result, firms can time payments within a contract to prevent hassle costs from dissuading customers from entering into profitable long-term contracts.

Roaming Hack, “There is a way to cancel your cell phone without paying an early termination fee”, http://roaminghack.blogspot.com/ (accessed October 24, 2007). 
Table A- 3: Logit models of discount choice in lab experiment A-4

\begin{tabular}{|c|c|c|c|c|c|}
\hline Variable & (1) & (2) & $(3)^{+}$ & $(4)^{+}$ & $(5)^{+}$ \\
\hline $\begin{array}{l}\text { Condition } 2 \\
\text { (hassle) }\end{array}$ & $\begin{array}{c}1.210^{* * *} \\
(0.436)\end{array}$ & & $\begin{array}{c}1.235^{* * *} \\
(0.454)\end{array}$ & $\begin{array}{c}1.226 * * * \\
(0.438)\end{array}$ & $\begin{array}{c}1.208^{* * * *} \\
(0.437)\end{array}$ \\
\hline Level of hassle & & $\begin{array}{l}0.175^{*} \\
(0.099)\end{array}$ & & & \\
\hline Service quality & & & $\begin{array}{c}0.002 \\
(0.184)\end{array}$ & & \\
\hline $\begin{array}{l}\text { Likely offered } \\
\text { - discount in first } \\
\text { month } \\
\text { - discount in last } \\
\text { month }\end{array}$ & & & $\begin{array}{c}0.012 \\
(0.114) \\
0.102 \\
(0.116)\end{array}$ & & \\
\hline $\begin{array}{l}\text { Discount rates } \\
-3 \text { months }\end{array}$ & & & & $\begin{array}{c}0.115 \\
(0.215)\end{array}$ & \\
\hline - 12 months & & & & & $\begin{array}{l}-0.118 \\
(0.474)\end{array}$ \\
\hline Constant & $\begin{array}{c}-2.051^{* * *} \\
(0.354)\end{array}$ & $\begin{array}{c}-2.121^{* * *} \\
(0.495)\end{array}$ & $\begin{array}{c}-2.575^{* *} \\
(1.137) \\
\end{array}$ & $\begin{array}{c}-2.176^{* * *} \\
(0.428)\end{array}$ & $\begin{array}{c}-1.994 * * * \\
(0.420) \\
\end{array}$ \\
\hline Log-Likelihood & -72.694 & -75.251 & -72.278 & -72.554 & -72.663 \\
\hline
\end{tabular}

\section{Summary of Results Regarding Discount Rates}

In this section, we present more detail about the results on subjects' discount rates and hyperbolic discounting. Throughout our lab experiments, we find evidence for hyperbolic discounting. In lab experiment 1 that examined hassle at setup, we expect an effect of subject's discount rates on choices. Our results confirm that discount rates affect choices, but our effect is robust to the effect of subject's discount rates. In lab experiments 2 through 5 and A-2 through A-4, we do not find a positive effect of discount rates on choosing a discount at the time of hassle.

Lab experiment 1: We measured a context-specific 3-month discount rate and 3- and 12month discount rates that abstract from the context of the lab experiment. None of the discount 
rates are significantly different across conditions (see Table A-4). The context-independent discount rate for three months is greater than for 12 months, which indicates hyperbolic discounting ( 1.483 vs. $0.603, \mathrm{p}=0.000$ ). As illustrated in Table 7 of the main paper, the contextindependent discount rates significantly affect plan choice but do not mitigate the effect of our main variables.

Table A- 4: Discount rates in lab experiment 1

\begin{tabular}{lccc}
\hline & $\begin{array}{l}\text { Condition 1: No } \\
\text { hassle }\end{array}$ & Condition 2: Hassle & p-value \\
\hline $\begin{array}{l}\text { Context-specific discount rates } \\
-3 \text { months }\end{array}$ & 2.204 & 2.421 & 0.636 \\
Context-independent discount rate & & & \\
-3 months & 1.423 & 1.541 & 0.697 \\
-12 months & 0.645 & 0.562 & 0.411 \\
\hline
\end{tabular}

Lab experiment 2: We measure context-specific and context-independent discount rates for 3- and 6-months. In both instances the 3-month discount rate is significantly greater than the 6month discount rate, indicating hyperbolic discounting (context-specific 1.781 vs. 1.314, $\mathrm{p}=0.000$; context-independent 1.508 vs. $1.073, \mathrm{p}=0.000$ ). None of the discount rates significantly differ across conditions (Table A- 5). As illustrated in Table 8 of the main paper, they also do not affect choice of the discounts.

Table A- 5: Discount rates in lab experiment 2

\begin{tabular}{lccc}
\hline & Condition 1: No hassle & Condition 2: Hassle & p-value \\
\hline Context-specific discount rates & & & \\
-3 months & 1.891 & 1.653 & 0.457 \\
-6 months & 1.230 & 1.330 & 0.881 \\
Context-independent discount rate & & & \\
-3 months & 1.491 & 1.528 & 0.899 \\
-6 months & 1.051 & 1.098 & 0.797 \\
\hline
\end{tabular}

Lab experiment 3: We measure context-specific and context-independent discount rates for 1- and 6-month periods. The 1-month context-specific discount rates are significantly greater 
than the 6-month discount rates, indicating hyperbolic discounting (6.632 vs. 2.016, p=0.000). The context-independent discount rates are not significantly different (1.125 vs. 0.963).

Lab experiment 4: We measure 3-month and 6-month context-specific and contextindependent discount rates. We find that 3-month discount rates are higher than 6-month discount rates, indicating hyperbolic discounting (context-specific: 2.264 vs. 1.475, contextindependent: 1.341 vs. 0.861).

Lab experiment 5: We measure context-independent discount rates for 3- and 12-months. The 3-month discount rates are significantly greater than the 12-month discount rates, indicating hyperbolic discounting (1.064 vs. $0.507, \mathrm{p}=0.000)$. The discount rates do not significantly differ across conditions (no-hassle vs. hassle conditions: 3 -months 0.999 vs. 1.129 , p=0.300; 12 months 0.471 vs. $0.544, \mathrm{p}=0.232$ ). As illustrated in Table 13 in the main paper, they also do not affect choice of the discounts.

Lab experiment A-2: We measure context-specific and context-independent discount rates for 3- and 6-months. In both instances the 3-month discount rate is significantly greater than the 6-month discount rate, indicating hyperbolic discounting (context-specific 2.689 vs. 1.897, $\mathrm{p}=0.000$; context-independent 1.094 vs. $0.794, \mathrm{p}=0.000$ ). None of the discount rates significantly differ across conditions (Table A- 6). As illustrated in Table A-1, they also do not affect choice of the discounts.

Table A- 6: Discount rates in lab experiment A-2

\begin{tabular}{lccc}
\hline & $\begin{array}{l}\text { Condition 1: No } \\
\text { hassle }\end{array}$ & Condition 2: Hassle & p-value \\
\hline Context-specific discount rates & & & 0.803 \\
-3 months & 2.653 & 2.774 & 0.535 \\
-6 months & 1.771 & 1.959 & 0.843 \\
Context-independent discount rate & & & 0.603 \\
- - 3 months & 1.080 & 1.132 & 0.830 \\
-6 months & 0.743 & & \\
\hline
\end{tabular}


Lab experiment A-3: We measure context-specific and context-independent discount rates for 3 and 12 months. In both instances the 3-month discount rate is significantly greater than the 12-month discount rate, indicating hyperbolic discounting (context-specific 1.830 vs. 0.837, $\mathrm{p}=0.000$; context-independent 1.496 vs. $0.658, \mathrm{p}=0.000$ ). None of the discount rates significantly differ across conditions (Table A- 7). As illustrated in Table A-3, they also do not affect choice of the discounts.

Table A- 7: Discount rates in lab experiment A-3

\begin{tabular}{lccc}
\hline & Condition 1: No hassle & Condition 2: Hassle & p-value \\
\hline Context-specific discount rates & & & 0.219 \\
-3 months & 2.083 & 1.649 & 0.729 \\
-12 months & 0.876 & 0.841 & 0.524 \\
Context-independent discount rate & & & 0.670 \\
-3 months & 1.604 & 1.441 & 0.652 \\
-12 months & 0.691 & & \\
\hline
\end{tabular}

Lab experiment A-4: We measure context-independent discount rates for 3- and 12-month periods. The 3-month discount rates are significantly greater than the 12-month discount rates, indicating hyperbolic discounting ( 0.986 vs. $0.478, \mathrm{p}=0.000)$. The discount rates do not significantly differ across conditions (3-months: 0.927 vs. $1.041, \mathrm{p}=0.277 ; 12$-months: 0.466 vs. 0.490, $\mathrm{p}=0.743$ ). As illustrated in Table A-3, they also do not affect choice of the discounts. 